\title{
Design and Evaluation of a Polypeptide That Mimics the Integrin Binding Site for EDA Fibronectin to Block Profibrotic Cell Activity
}

\author{
Lin Zhang ${ }^{1}$, Hongyu Yan ${ }^{1}$, Yifan Tai ${ }^{1}$, Yueming Xue ${ }^{1}$, Yongzhen Wei ${ }^{1}$, Kai Wang ${ }^{1}$, Qiang Zhao ${ }^{1}$, \\ Shufang Wang ${ }^{1, *}$, Deling Kong ${ }^{1,2}$ and Adam C. Midgley ${ }^{1,2, *(\mathbb{D})}$
}

check for

updates

Citation: Zhang, L.; Yan, H.; Tai, Y.; Xue, Y.; Wei, Y.; Wang, K.; Zhao, Q.; Wang, S.; Kong, D.; Midgley, A.C. Design and Evaluation of a Polypeptide That Mimics the Integrin Binding Site for EDA Fibronectin to Block Profibrotic Cell Activity. Int. J. Mol. Sci. 2021, 22, 1575. https:// doi.org/10.3390/ijms22041575

Academic Editor: Alberto Spisni

Received: 1 December 2020

Accepted: 1 February 2021

Published: 4 February 2021

Publisher's Note: MDPI stays neutral with regard to jurisdictional claims in published maps and institutional affiliations.

Copyright: (C) 2021 by the authors Licensee MDPI, Basel, Switzerland. This article is an open access article distributed under the terms and conditions of the Creative Commons Attribution (CC BY) license (https:/ / creativecommons.org/licenses/by/ $4.0 /)$.
1 Key Laboratory of Bioactive Materials, Ministry of Education, College of Life Sciences, Nankai University, Tianjin 300071, China; 1120180455@nankai.edu.cn (L.Z.); 1120190538@nankai.edu.cn (H.Y.); 1120190539@nankai.edu.cn (Y.T.); 2120181163@nankai.edu.cn (Y.X.); 1120170431@nankai.edu.cn (Y.W.); 013053@nankai.edu.cn (K.W.); qiangzhao@nankai.edu.cn (Q.Z.); kongdeling@nankai.edu.cn (D.K.)

2 Rongxiang Xu Center for Regenerative Life Science, State Key Laboratory of Medicinal Chemical Biology, College of Life Sciences, Nankai University, Tianjin 300071, China

* Correspondence: wangshufang@nankai.edu.cn (S.W.); midgleyac@nankai.edu.cn (A.C.M.); Tel.: +86-1562-004-7851 (A.C.M.)

\begin{abstract}
Fibrosis is characterized by excessive production of disorganized collagen- and fibronectinrich extracellular matrices (ECMs) and is driven by the persistence of myofibroblasts within tissues. A key protein contributing to myofibroblast differentiation is extra domain A fibronectin (EDA-FN). We sought to target and interfere with interactions between EDA-FN and its integrin receptors to effectively inhibit profibrotic activity and myofibroblast formation. Molecular docking was used to assist in the design of a blocking polypeptide (antifibrotic 38-amino-acid polypeptide, AF38Pep) for specific inhibition of EDA-FN associations with the fibroblast-expressed integrins $\alpha_{4} \beta_{1}$ and $\alpha_{4} \beta_{7}$. Blocking peptides were designed and evaluated in silico before synthesis, confirmation of binding specificity, and evaluation in vitro. We identified the high-affinity EDA-FN C-C' loop binding cleft within integrins $\alpha_{4} \beta_{1}$ and $\alpha_{4} \beta_{7}$. The polypeptide with the highest predicted binding affinity, AF38Pep, was synthesized and could achieve specific binding to myofibroblast fibronectin-rich ECM and EDA-FN C-C' loop peptides. AF38Pep demonstrated potent myofibroblast inhibitory activity at $10 \mu \mathrm{g} / \mathrm{mL}$ and was not cytotoxic. Treatment with AF38Pep prevented integrin $\alpha_{4} \beta_{1}$-mediated focal adhesion kinase (FAK) activation and early signaling through extracellular-signal-regulated kinases 1 and 2 (ERK1/2), attenuated the expression of pro-matrix metalloproteinase 9 (MMP9) and pro-MMP2, and inhibited collagen synthesis and deposition. Immunocytochemistry staining revealed an inhibition of $\alpha$-smooth muscle actin ( $\alpha$-SMA) incorporation into actin stress fibers and attenuated cell contraction. Increases in the expression of mRNA associated with fibrosis and downstream from integrin signaling were inhibited by treatment with AF38Pep. Our study suggested that AF38Pep could successfully interfere with EDA-FN C-C' loop-specific integrin interactions and could act as an effective inhibitor of fibroblast of myofibroblast differentiation.
\end{abstract}

Keywords: blocking peptide; molecular docking; fibrosis; antifibrotic; EDA fibronectin; integrin $\alpha 4 \beta 1$; fibroblast; myofibroblast

\section{Introduction}

Fibrosis is a disease process characterized by excessive and disorganized extracellular matrix (ECM) deposition that leads to organ dysfunction and, in some cases, organ failure and death $[1,2]$. The principal cell types that contribute to fibrogenesis and the onset of fibrosis are $\alpha$-smooth muscle actin ( $\alpha$-SMA) stress fiber-positive and contractile myofibroblasts [3,4]. Myofibroblast-mediated progressive fibrosis can befall most organs and tissues, giving rise to multiple end-stage organ diseases, including scleroderma [5], myocardial 
infarction [6], liver cirrhosis [7], pulmonary disease [8], and chronic kidney disease [9], among others. The fibrotic ECM is comprised of large amounts of activated fibroblastand myofibroblast-synthesized collagen I; fibronectin (FN); the alternatively spliced variant of FN, extra domain A containing fibronectin (EDA-FN), and the glycosaminoglycan hyaluronan [10]. The classical view is that for activated fibroblasts to differentiate into myofibroblasts, transforming growth factor- $\beta 1$ (TGF- $\beta 1$ ) and a mechanically stiff ECM containing EDA-FN are necessary precursors and requirements $[2,4,11,12]$.

The protein structure of fibronectin consists of twelve type I domains, two type II domains, and fifteen type III domains containing the two alternatively spliced extra domain A (EDA) and extra domain B (EDB) domains, and a connecting segment (IIICS) that has a variable expression [13,14]. Cellular fibronectin that undergoes alternative splicing to include EDA is synthesized by fibroblasts, endothelial cells, myoblasts [15], and osteoblasts [16]; yet EDA-FN splice variant only appears to be expressed with implications in wound repair $[17,18]$, pathological fibrosis [19], and tumor development [20-22]. EDA-FN is difficult to detect in normal adult tissues and is only transiently expressed during embryogenesis [23]. Although uninjured adult EDA-FN-null mice are indistinguishable from wild-type mice, their injured counterparts demonstrated abnormal skin wound healing, ulcerations, and elevated inflammation at sites of injury [18]. Persistent accumulation of EDA-FN isoforms is observed in a range of human fibrotic disorders such as pulmonary fibrosis [19], liver fibrosis [22], keloid scars [24], and scleroderma [25]. Mouse genetic knockout EDA-FN-null models do not develop pulmonary fibrosis after bleomycin insult and showed reduced numbers of activated fibroblast to myofibroblast differentiation [26]. These findings demonstrated the indispensable roles that EDA-FN plays in the pathogenesis of fibrosis, and that its expression advances activated fibroblast to myofibroblast differentiation.

The detailed cellular mechanisms by which EDA-FN facilitates fibrotic responses have not yet been fully elucidated, but evidence suggests that interactions between latent TGF$\beta 1$ activation [27], EDA-FN-dependent increases in matrix stress-strain properties [28,29], and the activation of certain mechanotransducer integrin receptors to trigger downstream signaling and transcriptional activity [30-32] cumulate and drive the myofibroblast differentiation process. It is without doubt that fibronectin association with cells is complex, binding a string of cell surface receptors via a multitude of binding domains. The integrin family are transmembrane dimeric receptors that transmit mechano-transduction signals from the extracellular matrix (ECM) to the intracellular cytoskeleton and vice versa, to drive both cellular and ECM remodeling responses. The type III domains of FN contain RGD and PHSRN amino acid motifs that can bind FN-recognition sites within integrins $\alpha_{5} \beta_{1}, \alpha_{\mathrm{IIb}} \beta_{3}, \alpha_{\mathrm{V}} \beta_{3}$ [33] and $\alpha_{3} \beta_{1}$ [34], to promote cell adhesion and activate integrin signaling that drives FN filament assembly [35-37]. In the context of fibrogenesis, research by Shinde et al. [38] and Kohan et al. [32] on EDA-FN/integrin interactions demonstrated that the fibroblast-expressed integrins $\alpha_{4} \beta_{1}$ (also known as VLA-4) and $\alpha_{4} \beta_{7}$ (also known as LPAM-1) played different but related roles in mediating fibroblast to myofibroblast formation, respectively. Integrin $\alpha_{4} \beta_{7}$-mediated EDA-FN binding induced myofibroblast-associated stress fiber formation and thus, contractility in murine lung fibroblasts [32], whereas integrin $\alpha_{4} \beta_{1}$ activation by EDA-FN promoted profibrotic ECM synthesis and subsequent matrix stiffening in human dermal fibroblasts [38]. Therefore, signaling transduction through both $\alpha_{4} \beta_{7}$ and $\alpha_{4} \beta_{1}$ are key events that ultimately lead to mature myofibroblast transdifferentiation. The research identified that the integrin interactions with the EDGIHEL motif, which is exclusively located within a polypeptide exposed loop at the EDA $C^{\prime}-C$ region, was causative of downstream profibrotic responses. In addition, it was suggested that recombinant fragments of EDA could be used to interfere with and block EDA-FN induction of myofibroblast activation [28]. However, it was later shown that binding of recombinant EDA-FN C-C ${ }^{\prime}$ loop peptides to integrin $\alpha_{4} \beta_{1}$ was sufficient to reproduce the fibrotic response [38] and may indicate that peptides derived from EDA provoke myofibroblast differentiation responses under pathological conditions. 
The antibodies IST-9 [28,29] and F8 [39,40] can target EDA-FN and mask a large portion of protein from its interaction sites, essentially resulting in off-target blockade of functionality. Therapeutic vaccination against EDA-FN produced by stromal myofibroblasts was shown to attenuate the progression of metastatic breast cancer [41]. Whilst antibodies have proven effective in preventing fibroblast to myofibroblast differentiation $[28,29]$ and in the antagonistic blockade of integrin $\alpha_{4}$ subunit-mediated activities [42], their use as a therapeutic option is limited given the cost and methodology of their production, risk of immune activation, and risk of off-target effects attributed to the large quaternary structure and size $(\sim 150 \mathrm{kDa})$ of antibodies interfering with critical protein-protein interactions. Small blocking polypeptides offer an attractive alternative and can be designed to bind and block regions of proteins with high specificity. Small peptides can also be synthesized at a decreased cost, have long-term stability, and can increase efficacy of a variety of treatment options. For example, peptides can be easily incorporated into biomaterials, or conjugated to bioimaging probes for more complex therapeutic usage. Therefore, this investigation aimed to use in silico molecular docking analysis to identify the EDA-FN C-C' loop's binding regions on a newly generated integrin $\alpha_{4} \beta_{1}$ receptor model and on the resolved $\alpha_{4} \beta_{7}$ receptor model. The new affinity and contact data were then used to design polypeptides that mimic the receptor binding site and block any EDA-FN C-C ${ }^{\prime}$ loop interactions with its cellular receptors. The resultant blocking polypeptide with the highest binding affinity (named AF38Pep) was assessed for potential to attenuate TGF- $\beta 1$ stimulated myofibroblast formation, block integrin $\alpha_{4} \beta_{1}$ signaling, and prevent the subsequent induction of profibrotic genes. The advantage of using blocking peptides in this way is to allow for the interference of ligand site-specific interactions with receptors, without disrupting the numerous other conveyed functions of EDA-FN and FN. Overall, we showed that our EDA-FN blocking peptide attenuated EDA-FN/integrin $\alpha_{4} \beta_{1}$-mediated myofibroblast differentiation and profibrotic ECM generation, revealing an accessible candidate for effective antifibrotic therapies.

\section{Results}

\subsection{Molecular Docking to Predict the Integrin $\alpha_{4} \beta_{1} / \beta_{7}$ Receptor Biding Site for EDA-FN}

The C-C' loop of the EDA-FN protein has been shown to interact with integrin $\alpha_{4} \beta_{1}$ and integrin $\alpha_{4} \beta_{7}$ [32,38]. Integrin $\alpha_{4} \beta_{7}$ has been resolved as a 3D crystal structure; however, $\alpha_{4} \beta_{1}$ has not yet been resolved. Therefore, in order to predict and compare receptor binding sites, an integrin $\alpha_{4} \beta_{1}$ model was required. To generate a working integrin $\alpha_{4} \beta_{1}$ model, the resolved structures for $\alpha_{4} \beta_{7}$ (3V4V; Figure 1A) and $\alpha_{5} \beta_{1}(4 \mathrm{WK} 2$; Figure 1B) were obtained from the PDB online repository. The integrin $\beta_{1}$ (ITB1_human) subunit shares $42.112 \%$ amino acid sequence homology with the integrin $\beta_{7}$ (ITB7_human) subunit. Thus, the ITB7_human amino acid sequence was used as a reference sequence and the 3D structure of the integrin $\beta_{7}$ subunit from the $\alpha_{4} \beta_{7}$ model was used as a template upon which the integrin $\beta_{1}$ subunit was mapped (Figure 1C). A structural comparison with the $\beta_{1}$ subunit conformation and orientation taken from the $\alpha_{5} \beta_{1}$ model showed that the new $\beta_{1}$ subunit model had protein structural domains within similar, if not identical, regions of the subunit. Next, the $\alpha_{4}$ subunit from the $\alpha_{4} \beta_{7}$ model, and the new $\beta_{1}$ subunit model, were compiled into a single receptor model (Figure 1D). H-bonds and metal ions were reassigned before validation using PROCHECK and Verify3D protein model analysis software. 
A

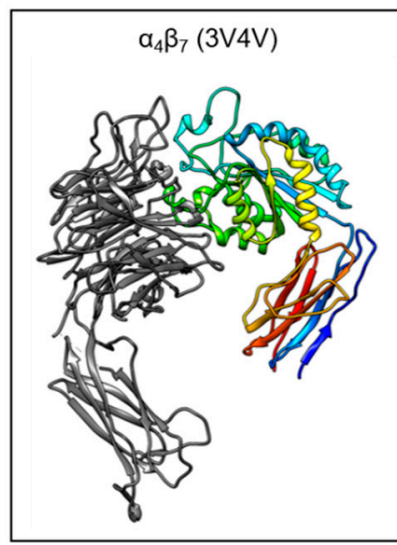

B

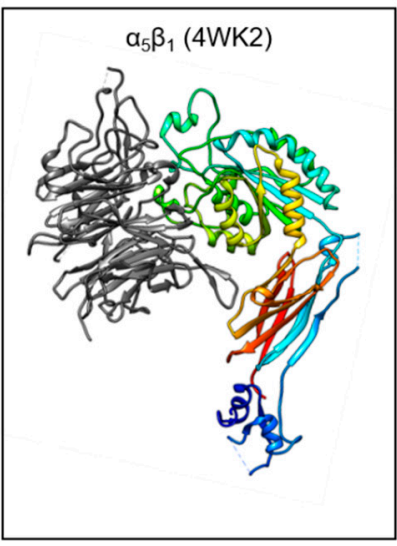

C

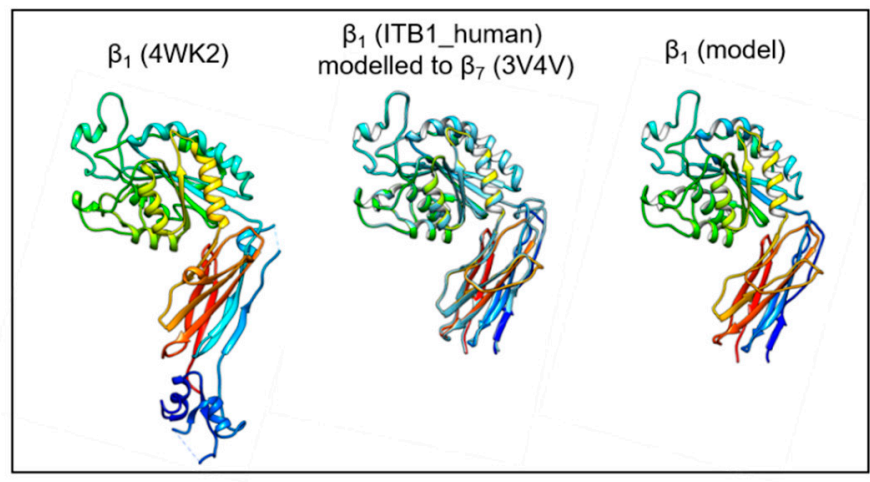

D

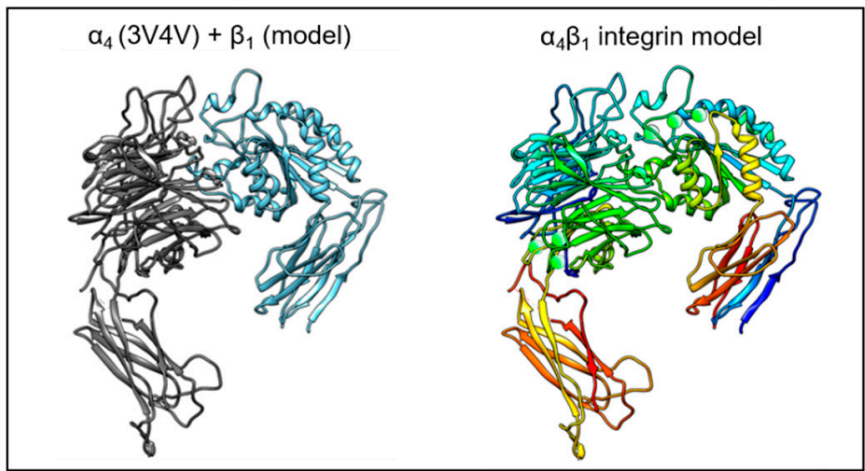

Figure 1. Generation of the integrin $\alpha_{4} \beta_{1}$ protein model. The process of generating a working integrin $\alpha_{4} \beta_{1}$ receptor protein model was as follows: (A) The $\alpha_{4} \beta_{7}$ resolved head domain model (PDB code $3 \mathrm{~V} 4 \mathrm{~V}$ ) and (B) the $\alpha_{5} \beta_{1}$ resolved head domain model (PDB code $4 \mathrm{WK} 2$ ) were utilized as templates for $\alpha_{4}$ and $\beta_{1}$ subunits, respectively. (C) The $\beta_{1}$ subunit (4WK2) was mapped using the ITB1_human peptide sequence and the $\beta_{7}$ subunit $(3 \mathrm{~V} 4 \mathrm{~V})$ as references, to generate a $\beta_{1}$ subunit model in active conformation. (D) The $\alpha_{4}(3 \mathrm{~V} 4 \mathrm{~V})$ and newly generated $\beta_{1}$ model subunits (left image) were compiled into a single $\alpha_{4} \beta_{1}$ integrin model (right image) with H-bonds and metal ions (green spheres).

The $\alpha_{4} \beta_{7}$ model and the new $\alpha_{4} \beta_{1}$ receptor model were examined for potential binding of the C-C' loop of EDA-FN. Across five separate grid analyses, which altogether covered the entirety of the receptor models' surfaces, only the grid that contained the head of the receptor binding cleft returned viable binding affinity data for both integrin receptors (Figure 2A). The top seven binding modes all had similar binding orientations and were aligned in the same directionality (Figure 2B). Binding mode AutoDock affinity scores ranged from between -5 to $5 \mathrm{kcal} / \mathrm{mol}$, with 6 of the 7 modes falling within the negative range, suggesting stronger indications for ligand binding at this receptor site. An assessment of the receptors' electrostatic potentials (Figure 2C) indicated that the majority of the ligand chain tended towards the positively charged regions $(0-5 \mathrm{kT} / \mathrm{e})$ of the receptor 
binding cleft, which suggests stronger electrostatic associations between the amino acids of the ligand and the amino acids of the receptor binding cleft. The amino acids within $3 \AA$ of contact distance were calculated and potential hydrogen bond donors were noted (Table 1). The data showed the amino acids with the strongest predicted binding potentials and suggested that shared EDA-FN binding motifs were present within both integrin $\beta_{1}$ and $\beta_{7}$ subunits. Figure 3 shows the EDA-FN peptide within $3 \AA$ contact distance with the predicted binding amino acids of integrin $\alpha_{4}$ (Figure 3A) and integrin $\beta_{1}$ (Figure 3B). These results provided sufficient evidence and information from which to base the design of peptides that mimic the integrin binding site for the $C-\mathrm{C}^{\prime}$ loop of EDA-FN.

A

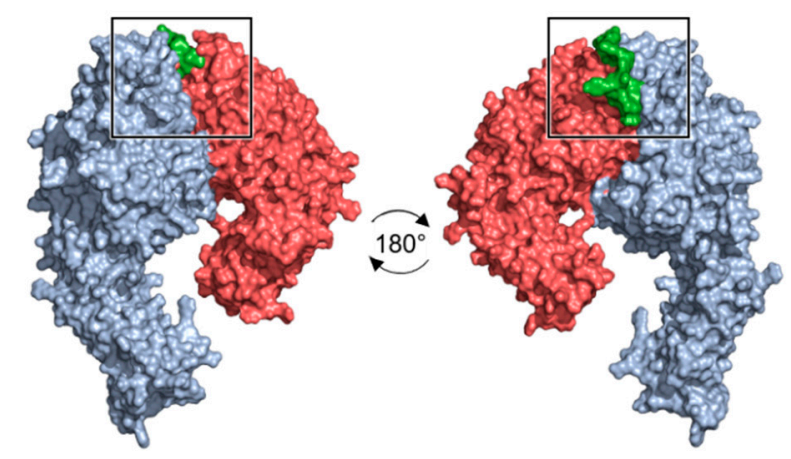

B

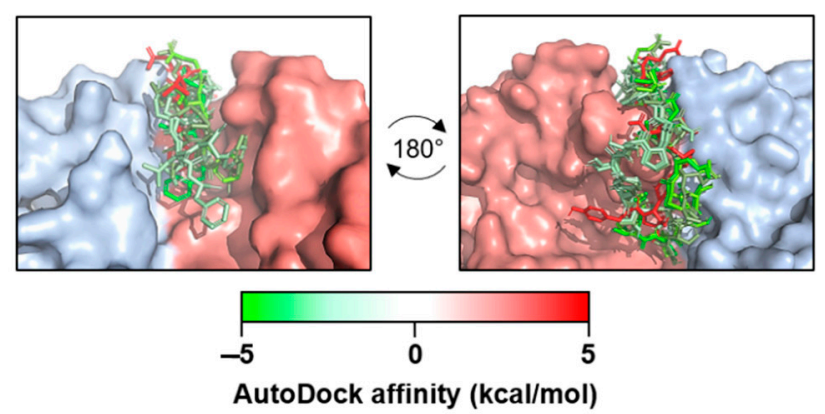

C

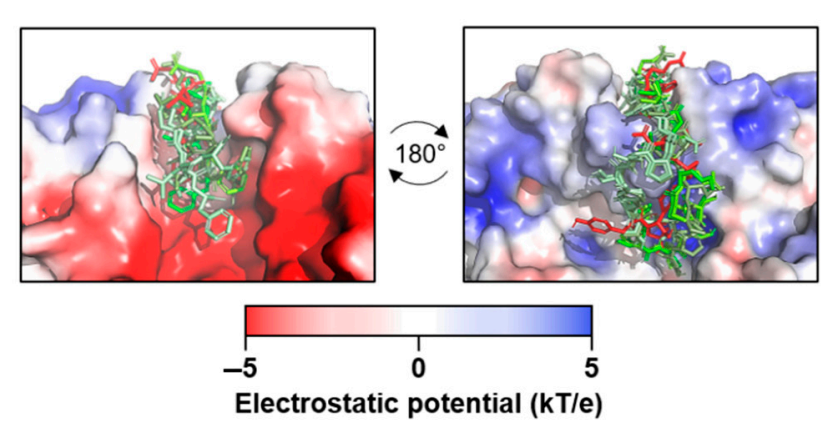

Figure 2. Molecular docking analysis of extra domain A fibronectin (EDA-FN) peptide domain binding to the $\alpha_{4} \beta_{1}$ receptor model. (A) The -TYSSPEDGHIEL- peptide domain of the EDA-FN protein (green) was utilized as a ligand for molecular docking analysis to the integrin $\alpha_{4}$ (blue) $\beta_{1}$ (red) receptor model. From the areas of the receptor analyzed, only the receptor binding cleft (boxed region) returned valid affinity score values. A $180^{\circ}$ rotation is shown in order to visualize the peptide within the receptor binding cleft. (B) The top 7 binding modes of the EDA-FN peptide within the integrin receptor binding cleft. Green $(-5)$ to red $(+5)$ gradient colorization relates to the AutoDock affinity $(\mathrm{kcal} / \mathrm{mol})$ scores. (C) The electrostatic potential $(\mathrm{kT} / \mathrm{e})$ of the receptor binding cleft was predicted and is shown as a red $(-5)$ to blue $(+5)$ gradient. Note that the peptide had an overall stronger binding mode in the positive region of the binding cleft. 
Table 1. Predicted integrin $\alpha_{4} \beta_{1} / \beta_{7}$ amino acids with contact with the EDA-FN peptide.

\begin{tabular}{|c|c|c|c|}
\hline Mode & Score & Subunit & Integrin Amino Acid in Contact $(\leq 3 \AA)$ \\
\hline 1 & -5.0 & $\begin{array}{l}\alpha_{4} \\
\beta_{1} \\
\beta_{7}\end{array}$ & $\begin{array}{l}\mathrm{E}^{121}, \mathrm{D}^{123},{ }^{*} \mathrm{~N}^{124},{ }^{*} \mathrm{~K}^{149}, \mathrm{I}^{154}, \mathrm{~K}^{155},{ }^{*} \mathrm{~N}^{156}, \mathrm{E}^{157},{ }^{*} \mathrm{~N}^{158},{ }^{*} \mathrm{~K}^{159}, \mathrm{~F}^{191}, \mathrm{G}^{192} \\
\mathrm{~V}^{192}, \mathrm{M}^{193}, \mathrm{I}^{196}, \mathrm{~S}^{197}, \mathrm{~T}^{198}, \mathrm{~T}^{199}, \mathrm{P}^{200}, * \mathrm{~A}^{201},{ }^{202} \mathrm{~K}^{202}, \mathrm{~L}^{203}, \mathrm{P}^{206}, \mathrm{C}^{207}, \mathrm{~T}^{208}, \mathrm{~S}^{209}, \mathrm{~N}^{244}, \mathrm{~L}^{245}, \\
{ }^{*} \mathrm{G}^{291}, \mathrm{H}^{312} \\
\mathrm{~V}^{201}, \mathrm{P}^{203}, \mathrm{~V}^{205}, \mathrm{~S}^{206}, \mathrm{~T}^{207}, \mathrm{~V}^{208}, \mathrm{P}^{209}, \mathrm{~S}^{210},{ }^{*} \mathrm{~K}^{211}, \mathrm{~L}^{212}, \mathrm{P}^{215}, \mathrm{C}^{216}, \mathrm{P}^{217}, \mathrm{~T}^{218},{ }^{*} \mathrm{~N}^{254}, \mathrm{~L}^{255},{ }^{*} \mathrm{G}^{301}\end{array}$ \\
\hline 2 & -4.4 & $\begin{array}{l}\alpha_{4} \\
\beta_{1} \\
\beta_{7}\end{array}$ & $\begin{array}{l}\mathrm{E}^{121}, \mathrm{D}^{123},{ }^{*} \mathrm{~N}^{124}, \mathrm{R}^{147},{ }^{*} \mathrm{~K}^{149}, \mathrm{I}^{154}, \mathrm{~K}^{155},{ }^{*} \mathrm{~N}^{156},{ }^{*} \mathrm{~K}^{159}, \mathrm{Y}^{220} \\
\mathrm{Y}^{153}, \mathrm{~V}^{192}, \mathrm{M}^{193}, \mathrm{~T}^{199}, \mathrm{P}^{200}, \mathrm{~A}^{201},{ }^{*} \mathrm{~K}^{202}, \mathrm{~L}^{203}, \mathrm{P}^{206}, \mathrm{C}^{207}, \mathrm{~T}^{208}, \mathrm{G}^{243},{ }^{*} \mathrm{~N}^{244} \\
\mathrm{~V}^{201}, \mathrm{P}^{203}, \mathrm{P}^{209}, \mathrm{~S}^{210},{ }^{*} \mathrm{~K}^{211}, \mathrm{~L}^{212}, \mathrm{P}^{215}, \mathrm{C}^{216}, \mathrm{P}^{217}, \mathrm{~T}^{218},{ }^{*} \mathrm{~N}^{254}, \mathrm{~L}^{255}\end{array}$ \\
\hline 3 & -3.3 & $\begin{array}{l}\alpha_{4} \\
\beta_{1} \\
\beta_{7}\end{array}$ & $\begin{array}{l}\mathrm{I}^{154}, \mathrm{~K}^{155},{ }^{*} \mathrm{~N}^{156}, \mathrm{E}^{157}, \mathrm{~N}^{158}, \mathrm{~K}^{159}, \mathrm{~K}^{190}, \mathrm{~F}^{191}, \mathrm{G}^{192} \\
\mathrm{Y}^{153}, \mathrm{~T}^{199}, \mathrm{P}^{200},{ }^{*} \mathrm{~A}^{201},{ }^{*} \mathrm{~K}^{202},{ }^{*} \mathrm{R}^{204},{ }^{*} \mathrm{~N}^{205}, \mathrm{P}^{206}, \mathrm{C}^{207}, \mathrm{~T}^{208}, \mathrm{~L}^{245} \\
\mathrm{~V}^{201}, \mathrm{P}^{203}, \mathrm{P}^{209}, \mathrm{~S}^{210},{ }^{*} \mathrm{~K}^{211}, \mathrm{~L}^{212},{ }^{*} \mathrm{R}^{213}, \mathrm{P}^{215}, \mathrm{C}^{216}, \mathrm{~T}^{218}, \mathrm{~L}^{255}\end{array}$ \\
\hline 4 & -3.1 & $\begin{array}{l}\alpha_{4} \\
\beta_{1} \\
\beta_{7}\end{array}$ & $\begin{array}{l}\mathrm{I}^{154}, \mathrm{~N}^{156}, \mathrm{E}^{157}, \mathrm{~K}^{159}, \mathrm{~K}^{190}, \mathrm{~F}^{191}, \mathrm{Y}^{220}, \mathrm{~W}^{221} \\
\mathrm{~S}^{197}, \mathrm{~T}^{198}, \mathrm{P}^{200}, \mathrm{~A}^{201},{ }^{*} \mathrm{~K}^{202},{ }^{*} \mathrm{R}^{204}, \mathrm{P}^{206}, \mathrm{C}^{207}, \mathrm{~T}^{208}, \mathrm{~S}^{209},{ }^{*} \mathrm{~N}^{244}, \mathrm{~L}^{245} \\
\mathrm{~V}^{201}, \mathrm{P}^{203}, \mathrm{P}^{209}, \mathrm{~S}^{210},{ }^{*} \mathrm{~K}^{211}, \mathrm{~L}^{212},{ }^{*} \mathrm{R}^{213}, \mathrm{P}^{215}, \mathrm{C}^{216}, \mathrm{P}^{217}, \mathrm{~T}^{218}, \mathrm{G}^{253},{ }^{*} \mathrm{~N}^{254}, \mathrm{~L}^{255}\end{array}$ \\
\hline 5 & -2.6 & $\begin{array}{l}\alpha_{4} \\
\beta_{1} \\
\beta_{7}\end{array}$ & $\begin{array}{l}\mathrm{E}^{121}, \mathrm{D}^{123}, \mathrm{~N}^{124}, \mathrm{I}^{154}, \mathrm{~K}^{155},{ }^{*} \mathrm{~N}^{156}, \mathrm{E}^{157}, \mathrm{~N}^{158}, \mathrm{~K}^{159}, \mathrm{~K}^{190}, \mathrm{~F}^{191}, \mathrm{G}^{192}, \mathrm{Y}^{220}, \mathrm{~W}^{221} \\
\mathrm{Y}^{153},{ }^{*} \mathrm{~S}^{197}, \mathrm{~T}^{199}, \mathrm{P}^{200},{ }^{*} \mathrm{~A}^{201},{ }^{*} \mathrm{~K}^{202}, \mathrm{R}^{204}, \mathrm{~N}^{205}, \mathrm{P}^{206}, \mathrm{C}^{207}, \mathrm{~T}^{208}, \mathrm{G}^{243}, \mathrm{~N}^{244} \\
\mathrm{P}^{209}, \mathrm{~S}^{210},{ }^{*} \mathrm{~K}^{211}, \mathrm{~L}^{212},{ }^{*} \mathrm{R}^{213}, \mathrm{P}^{215}, \mathrm{C}^{216}, \mathrm{~T}^{218}, \mathrm{G}^{253}, \mathrm{~N}^{254}\end{array}$ \\
\hline 6 & -2.2 & $\begin{array}{l}\alpha_{4} \\
\beta_{1} \\
\beta_{7}\end{array}$ & $\begin{array}{l}\mathrm{E}^{121},{ }^{*} \mathrm{~N}^{124}, \mathrm{R}^{147}, \mathrm{I}^{154}, \mathrm{~K}^{155},{ }^{*} \mathrm{~N}^{156},{ }^{*} \mathrm{E}^{157},{ }^{*} \mathrm{~N}^{158},{ }^{*} \mathrm{~K}^{159} \\
\mathrm{~T}^{191}, \mathrm{~V}^{192}, \mathrm{~T}^{198},{ }^{*} \mathrm{~T}^{199}, \mathrm{P}^{200}, \mathrm{~A}^{201}, \mathrm{~K}^{202}, \mathrm{~L}^{203}, \mathrm{~T}^{208}, \mathrm{G}^{291}, \mathrm{G}^{292}, \mathrm{H}^{312} \\
\mathrm{~T}^{200}, \mathrm{~V}^{201}, \mathrm{~L}^{202},{ }^{*} \mathrm{~T}^{207}, \mathrm{~V}^{208}, \mathrm{P}^{209}, \mathrm{~S}^{210}, \mathrm{~K}^{211}, \mathrm{~L}^{212}, \mathrm{~T}^{218}, \mathrm{G}^{301}\end{array}$ \\
\hline 7 & +3.3 & $\begin{array}{l}\alpha_{4} \\
\beta_{1} \\
\beta_{7}\end{array}$ & $\begin{array}{l}\mathrm{I}^{154}, \mathrm{~K}^{155},{ }^{*} \mathrm{~N}^{156}, \mathrm{~N}^{158},{ }^{*} \mathrm{~K}^{159}, \mathrm{~F}^{191} \\
{ }^{*} \mathrm{~T}^{191}, \mathrm{~V}^{192},{ }^{*} \mathrm{~S}^{197},{ }^{*} \mathrm{~T}^{198}, \mathrm{~T}^{199}, \mathrm{P}^{200},{ }^{*} \mathrm{~A}^{201}, \mathrm{~K}^{202}, \mathrm{~L}^{203} \\
{ }^{*} \mathrm{~T}^{200}, \mathrm{~V}^{201},{ }^{*} \mathrm{~S}^{206},{ }^{*} \mathrm{~T}^{207}, \mathrm{~V}^{208}, \mathrm{P}^{209}, \mathrm{~S}^{210},{ }^{*} \mathrm{~K}^{211}, \mathrm{~L}^{212}\end{array}$ \\
\hline
\end{tabular}

* indicates predicted H-bond donor.

\subsection{Modeling and Synthesis of EDA-FN Blocking Polypeptide}

Based on the results from Table 1 and Figure 3, a series of candidate blocking polypeptides were designed and evaluated through stringent assessment by peptide folding and molecular docking. The best performing polypeptide (Figure 4A) was docked with the C-C' loop EDA-FN peptide and demonstrated a binding score of $\leq-5 \mathrm{kcal} / \mathrm{mol}$, suggesting strong binding potential. The designed peptide candidate had a cage-like conformation to mimic the integrin $\alpha_{4} \beta_{1}$ receptor binding cleft and the 3 finger-like protrusions from each subunit that had the highest interactivity with the EDA-FN peptide. Key features of the designed polypeptide are shown in Figure $4 \mathrm{~B}(\mathrm{I}-\mathrm{V})$. The valine-methionine cap (Figure 4B(I)) had the highest binding affinity to the $5^{\prime}$ end of the $C-C^{\prime}$ loop of EDA-FN and the upstream amino acids. The ISTTPAK motif from the $\beta_{1} / \beta_{7}$ subunit (Figure $4 B(I I)$ ) showed the most consistent representation across all predicted binding modes. A cysteine disulfide bridge was incorporated (Figure $4 \mathrm{~B}(\mathrm{III}, \mathrm{IV})$ ) to provide a folded apex, which allowed for the $\alpha_{4^{-}}$and $\beta_{1}$-like cages to flank either side of the EDA-FN peptide. The KNENKI motif from the $\alpha_{4}$ subunit (Figure $4 \mathrm{~B}(\mathrm{~V})$ ) was included to mimic the most reoccurring binding motif across predicted binding modes. Thus, this candidate antifibrotic 38-amino-acid polypeptide (AF38Pep) design (Figure 4C; sequence, VMPYISTTPAKPCTSENCGNSWYGGFKSKNENKIYFIN) was chosen for synthesis and subsequent testing using in vitro assays.

\subsection{Evaluation of Polypeptide Cytocompatibility and Antifibrotic Function}

To determine whether the blocking polypeptide had antifibrotic functionality or exhibited cytotoxicity, we incubated TGF- $\beta 1$-treated mouse dermal fibroblasts (NIH/3T3; Figure $5 \mathrm{~A}, \mathrm{~B}$ ) or human lung fibroblasts (HFL1; Figure $5 \mathrm{C}, \mathrm{D}$ ) with a $\log _{10}$ dilution range of AF38Pep. Over the course of $72 \mathrm{~h}$, TGF- $\beta 1$ induced the largest mRNA expression of the myofibroblast marker, $\alpha$-SMA, at the $48 \mathrm{~h}$ timepoint in NIH/3T3 cells (Figure $5 \mathrm{~A}$ ). Treatment with the blocking peptide significantly attenuated gene induction at $48 \mathrm{~h}$ in 
all concentrations tested. At the $72 \mathrm{~h}$ timepoint, $\alpha$-SMA mRNA expression was elevated in the untreated control group. However, only AF38Pep treatment at a concentration of $10 \mu \mathrm{g} / \mathrm{mL}$ was sufficient to significantly attenuate the $\alpha$-SMA mRNA upregulation, which suggested that $0.1-1 \mu \mathrm{g} / \mathrm{mL}$ polypeptide concentrations were not able to effectively inhibit the differentiation response over the $72 \mathrm{~h}$ duration of treatment. Cytotoxicity of AF38Pep was assessed to ensure the effects observed were not indicative of NIH/3T3 cell apoptosis (Figure 5B). Indeed, cells maintained a consistent growth pattern in response to TGF- $\beta 1$ stimulation, and results suggest that treatment with the polypeptide at either of the concentrations did not interfere with cell proliferation nor incur cell death. Similar results were observed when HFL1 cells were assessed for the potential of the blocking polypeptide to attenuate expression of $\alpha$-SMA (Figure 5C). The upregulation of $\alpha$-SMA mRNA expression by TGF- $\beta 1$ was significantly reduced by $0.1-10 \mu \mathrm{g} / \mathrm{mL}$ peptide at $48 \mathrm{~h}$, and only $10 \mu \mathrm{g} / \mathrm{mL}$ was sufficient for inhibition of expression at $72 \mathrm{~h}$. Assessment of AF38Pep toxicity to HFL1 cells (Figure 5D) indicated that the blocking effect was not detrimental to cell numbers.

\section{A}

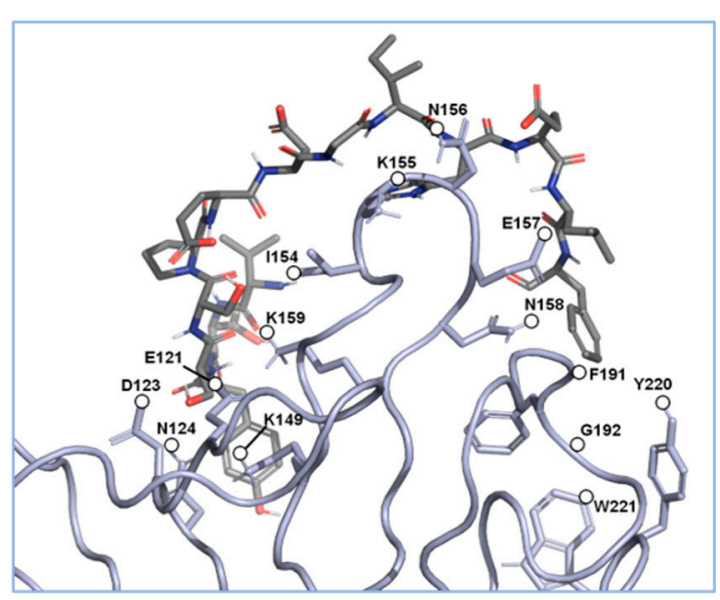

B

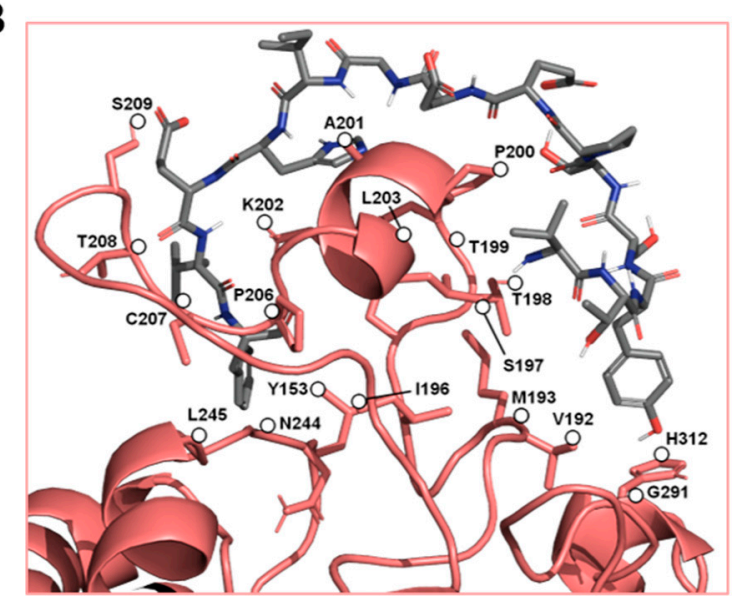

Figure 3. The predicted key binding amino acids of the triple loop structures from the $\alpha_{4}$ and $\beta_{1}$ subunits. The amino acids with the highest predicted binding affinities to the EDA-FN peptide (grey) are highlighted within (A) the $\alpha_{4}$ subunit triple loop finger-like domains of the integrin receptor cleft (blue), and (B) the $\beta_{1}$ subunit triple loop finger-like domains of the integrin receptor cleft (red). The $\beta_{1}$ subunit was used for visualization. 
A

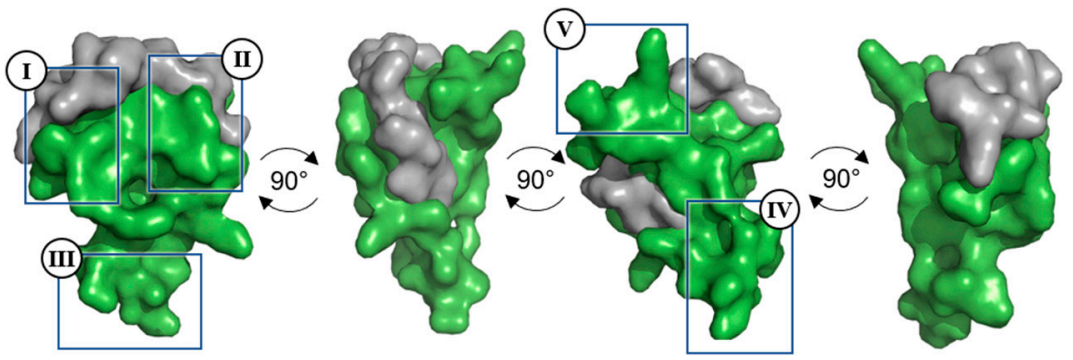

B
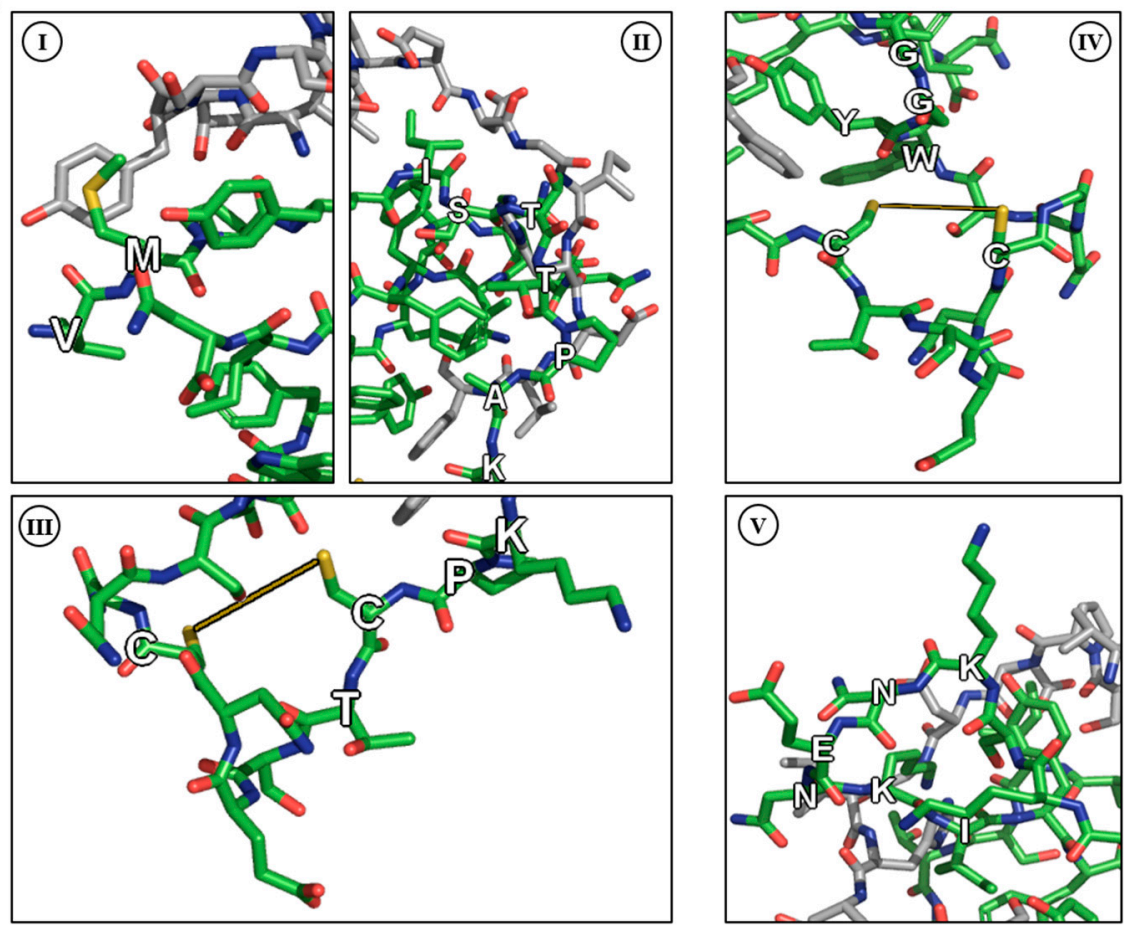

C AF38Pep 1-derived sequence

Val-Met-Pro-Tyr-Ile-Ser-Thr-Thr-Pro-Ala-Lys-Pro-Cys-Thr-Ser-Glu-Asn-Cys-Gly-Asn

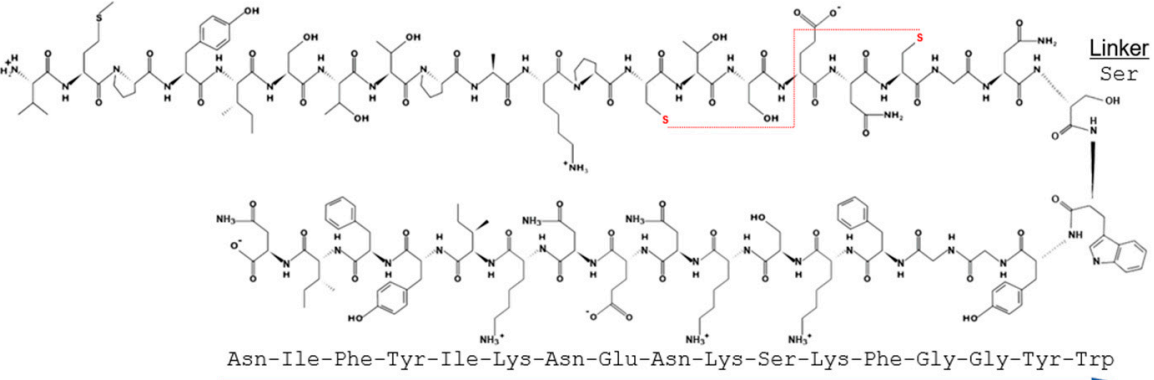

a4-derived sequence

Figure 4. Molecular docking analysis of the designed blocking polypeptide and key features. (A) The EDA-FN peptide (grey) was docked to the blocking polypeptide (green) derived from the polypeptide with the overall highest scores across all refinement analyses. A $360^{\circ}$ rotation is shown to visualize the wrapping and binding of the EDA-FN peptide to the blocking polypeptide, which mimics the integrin $\alpha_{4} \beta_{1} / \beta_{7}$ receptor binding site. Boxed regions I-IV are shown in (B) to highlight the key features of the designed blocking polypeptide. I, the VM cap; II, the ISTTPAK motif of the $\beta_{1} / \beta_{7}$ subunit; III and IV, the $\mathrm{C}=\mathrm{C}$ disulfide bridge to form the receptor and cage-like conformation; $\mathrm{V}$, the KNENKI motif of the $\alpha 4$ subunit. (C) The antifibrotic 38-amino-acid polypeptide (AF38Pep) polypeptide sequence structure, showing two peptide chains derived from integrins $\beta_{1}$ and $\alpha_{4}$, linked by a serine. Disulfide bridge is shown by a red dashed line, bridging the two cysteines. 

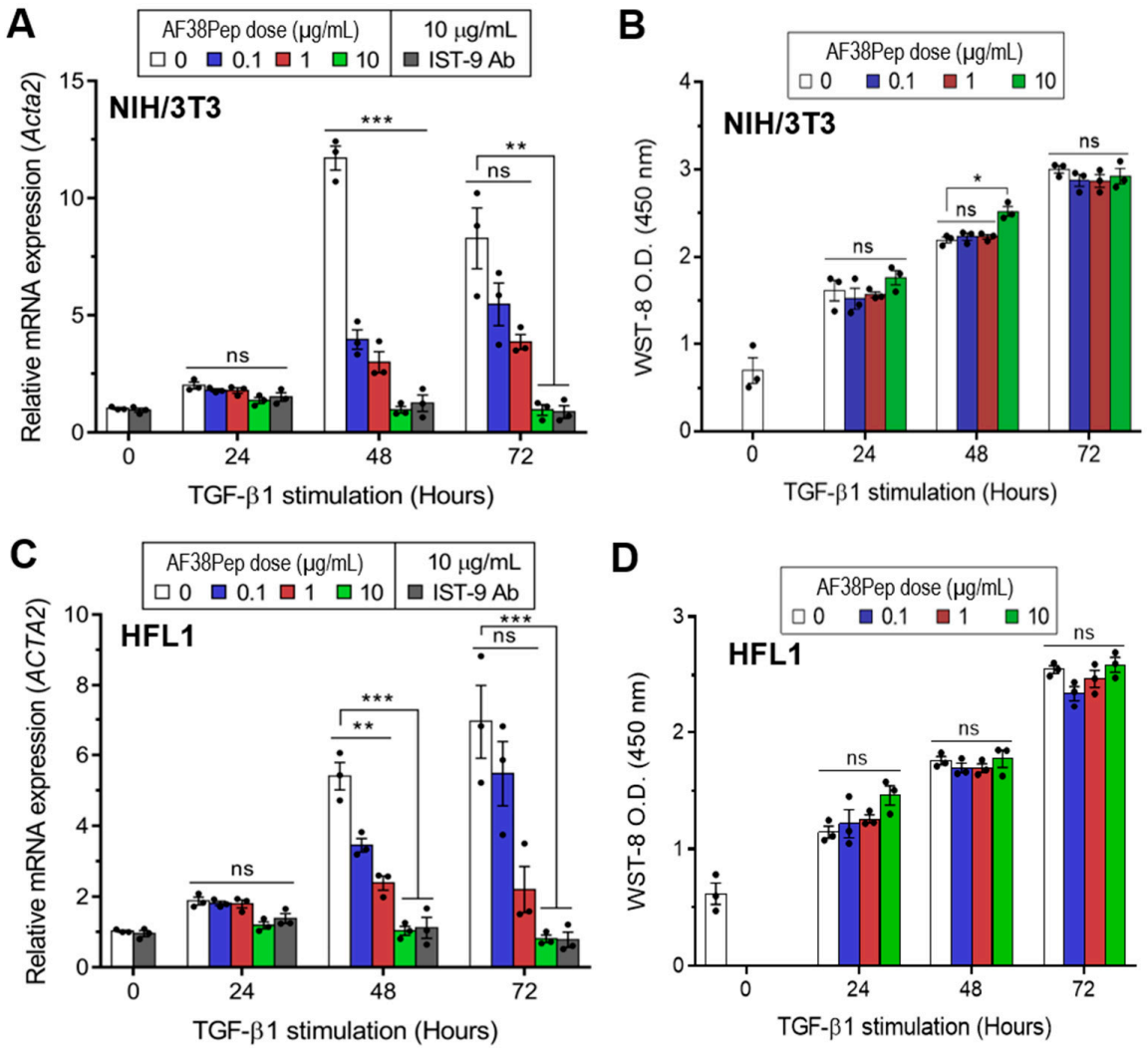

Figure 5. Cytocompatibility characteristics of the synthesized blocking polypeptide. (A) The ability for AF38Pep to attenuate transforming growth factor- $\beta 1$ (TGF- $\beta 1$ ) induced upregulation in expression of the myofibroblast marker, $\alpha$-smooth muscle actin ( $\alpha$-SMA), in mouse NIH/3T3 dermal fibroblast cells over $72 \mathrm{~h}$. (B) Cytotoxicity/proliferation assays in TGF- $\beta 1$ stimulated mouse NIH/3T3 dermal fibroblast cells over $72 \mathrm{~h}$. (C) The ability for AF38Pep to attenuate TGF- $\beta 1$ induced upregulation in expression of $\alpha$-SMA in human HFL1 lung fibroblast cells over $72 \mathrm{~h}$. (D) Cytotoxicity/proliferation assays in TGF- $\beta 1$ stimulated human HFL1 lung fibroblast cells over $72 \mathrm{~h}$. IST-9 antibody was used as a positive control for EDA-FN blockade. Data are representative of three independent experiments and displayed as the mean \pm S.E. Statistical analysis is shown as ${ }^{* * *} p \leq 0.001,{ }^{* *} p \leq 0.01,{ }^{*} p \leq 0.05$, and $\mathrm{ns}=$ no statistical significance $(p>0.05)$.

\subsection{Evaluation of Polypeptide Binding, Blocking Function and Specificity}

The designed AF38Pep blocking polypeptide was synthesized alongside three smaller peptides, each 12 amino acids in length. These smaller peptides were designated as follows: FN-EDA, a peptide sharing amino acid sequence with the $C-C^{\prime}$ loop of EDA-FN (TYSSPEDGIHEL); FN-RGD, a peptide derived from the integrin $\beta_{1}$ and $\beta_{3}$ subunitbinding RGD motif of fibronectin (YAVTGRGDSPAS); COL-RGD, a peptide derived from the integrin $\beta_{1}$ subunit-binding RGD motif of collagen I (GPKGDRGDAGPK). Isothermal calorimetry (ITC) was used to determine whether AF38Pep showed interactions with the small peptide FN-EDA (Figure 6A), or unintentional unspecific binding interactions with FN-RGD (Figure 6B) and COL-RGD (Figure 6C). Thermogram plots indicated that there was a detectable interaction between AF38Pep and FN-EDA, but not between AF38Pep and FNRGD or COL-RGD. The collated isogram plot (Figure 6D) reflected these interactions, as no $K_{A}$ could be determined for interactions with the peptides derived from RGD domains. A $K_{A}$ value was calculated for the binding interaction between AF38Pep and FN-EDA, giving evidence of specific binding, affinity and validating the molecular docking predictions used for polypeptide design. These data indicated that the AF38Pep blocking polypeptide was suitable for use for targeting EDA-FN and interfering with its binding to the integrin receptor cleft. 
A

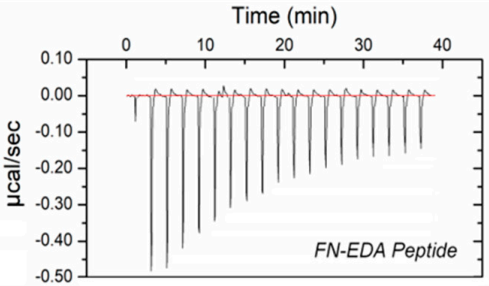

B

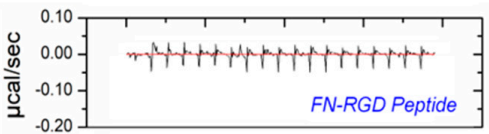

C

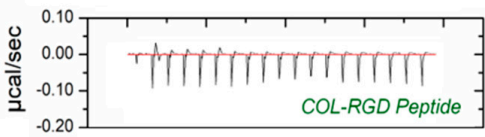

D

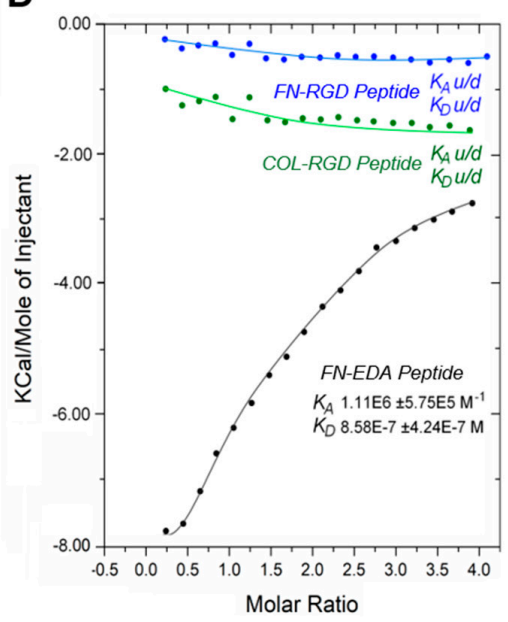

$\mathbf{E}$

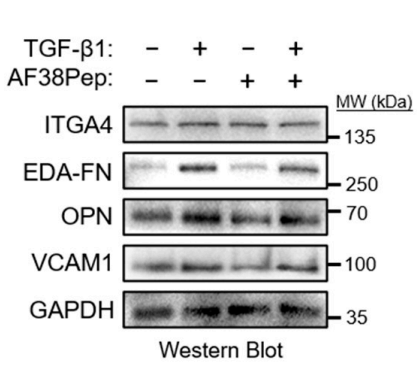

$\mathbf{F}$

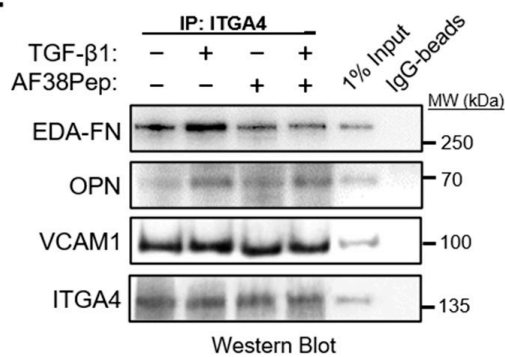

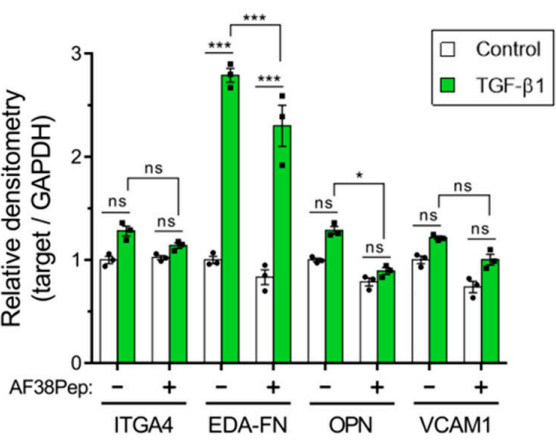

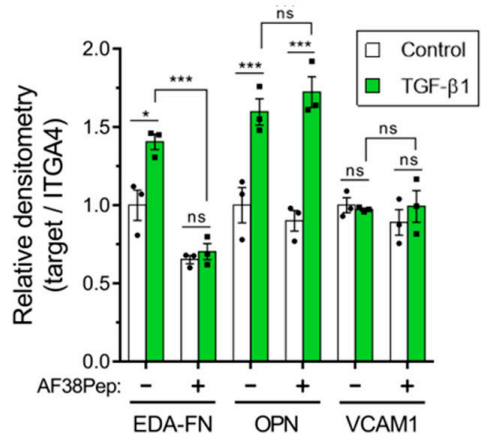

Figure 6. Binding specificity and blocking function of the synthesized blocking polypeptide. The designed blocking peptide was synthesized alongside 3 small test-binding peptides (FN-EDA, FNRGD, COL-RGD) and were assessed by isothermal calorimetry (ITC), and calorimetric heat traces were used to test whether the blocking peptide has specificity to bind peptides derived from (A) the predicted EDA binding ligand (FN-EDA, black), (B) the RGD-domain of EDA-FN and FN shown to bind integrin $\alpha_{4} \beta_{1} / \beta_{7}$ at a distal site (FN-RGD, blue), and (C) the RGD-domain of collagen I previously shown to bind different integrin subunits (COL-RGD, negative control, green). (D) The collated isogram is shown alongside predicted dissociation constants $\left(K_{D}\right)$ and association constants $\left(K_{A}\right)$, calculated using a 1:1 receptor site to ligand site binding mode. (E) Western blot analysis of integrin $\alpha_{4}$ protein (ITGA4), EDA-FN, osteopontin (OPN), and vascular cell adhesion protein-1 (VCAM1) total protein following $48 \mathrm{~h}$ TGF- $\beta 1$, AF38Pep or TGF- $\beta 1+A F 38$ Pep treatments. GAPDH was used as a loading control. Densitometry quantification is shown alongside. (F) Co-IP analysis of ITGA4 binding partners (EDA-FN, OPN, and VCAM1) following $48 \mathrm{~h}$ TGF- $\beta 1$, AF38Pep or TGF$\beta 1+\mathrm{AF} 38 \mathrm{Pep}$ treatments. Data are representative of three independent experiments and displayed as the mean \pm S.E. Statistical analysis is shown as ${ }^{* * *} p \leq 0.001,{ }^{*} p \leq 0.05$, and ns $=$ no statistical significance $(p>0.05)$. 
We next assessed the capability of AF38Pep to inhibit EDA-FN interactions with integrin $\alpha_{4}$ protein (ITGA4), and whether interactions with other ligands were also affected. Western blots indicated that the total protein for ITGA4 and its ligand, vascular cell adhesion protein-1 (VCAM1), remained unaffected following TGF- $\beta 1$ or AF38Pep treatments (Figure 6E). EDA-FN total protein significantly increased following TGF- $\beta 1$ stimulation compared to the control group. The TGF- $\beta 1$-driven EDA-FN protein increase was marginally, but significantly, attenuated by AF38Pep treatment. The protein expression of osteopontin (OPN), another ITGA4 ligand, was also significantly attenuated by AF38Pep treatment. To further assess whether AF38Pep interfered with ITGA4-ligand interactions, coimmunoprecipitation (Co-IP) assays were performed using anti-ITGA4 antibodies and Western blot was used to detect interacting proteins (Figure 6F). Co-IP showed that TGF- $\beta 1$ stimulation increased EDA-FN and OPN binding to ITGA4. The quantity of VCAM1ITGA4 binding was unaffected by cell treatments and remained at basal levels. AF38Pep specifically inhibited EDA-FN-ITGA4 interactions and did not influence OPN-ITGA4 binding. Taken together, immunoblots demonstrated that although fibroblasts continued to produce EDA-FN protein in response to TGF- $\beta 1$ stimulation, AF38Pep treatments inhibited EDA-FN binding to the integrin $\alpha 4$ receptor, without affecting the binding of other ligands.

To determine AF38Pep affinity for myofibroblast-synthesized ECM, AF38Pep was conjugated to Cy5 dye (AF38Pep-Cy5) and incubated with fixed ECM synthesized by either untreated control fibroblasts or differentiated myofibroblasts. First, localization was assessed by comparing AF38Pep-Cy5 labelling to pan-fibronectin (FN1) immunostaining (Figure 7A). In fibroblasts, some FN1 staining was observable, whereas little to no staining with AF38Pep-Cy5 was observed. In myofibroblasts, FN1 deposition increased and was clearly visualized. AF38Pep-Cy5 labelling also increased in myofibroblasts (red) and merged images showed AF38Pep-Cy5 colocalization with anti-FN1 staining (yellow) was prominent in areas of fibronectin deposition at cell membranes, although regions that were only labelled by FN1 immunostaining were also observed (green). We next compared staining patterns compared to IST-9 (EDA-FN antibody), and whether pretreatments would competitively interfere with labelling (Figure 7B). In fibroblasts, staining with either IST-9 or AF38Pep-Cy5 was minimal, regardless of the order of addition to cells. In myofibroblasts, AF38Pep-Cy5 labelled the upregulated EDA-FN production and pre-treatment blocked IST-9 staining. Similarly, when IST-9 pretreatments were applied, AF38Pep-Cy5 failed to label the elevated EDA-FN production. We further confirmed EDA-FN ECM specificity and competitive binding by incubating AF38Pep-Cy5 with cells treated with TGF- $\beta 1$ for 24 (early activated fibroblasts), 48 (late activated fibroblasts) and $72 \mathrm{~h}$ (differentiated myofibroblasts). The results demonstrated increased binding of AF38Pep to the fibrotic ECM, which correlated with the increasing time of TGF- $\beta 1$ treatment (Figure $7 \mathrm{C}$ ). The data showed significant increases in binding at $48 \mathrm{~h}$, compared to $0 \mathrm{~h}$ TGF- $\beta 1$ treatment. Similar results to the immunocytochemistry were observed when pretreatments with IST-9 were made; IST-9 attenuated AF38Pep-Cy5 binding to EDA-FN protein, thereby decreasing the detectable epifluorescence signal over the course of the $72 \mathrm{~h}$ TGF- $\beta 1$ treatment. Taken together, these data suggested that binding sites for AF38Pep-Cy5 were masked by IST- 9 pretreatments. AF38Pep also had the capacity to interfere with IST-9 binding, indicating binding specificity of AF38Pep for the EDA-FN protein. 
A

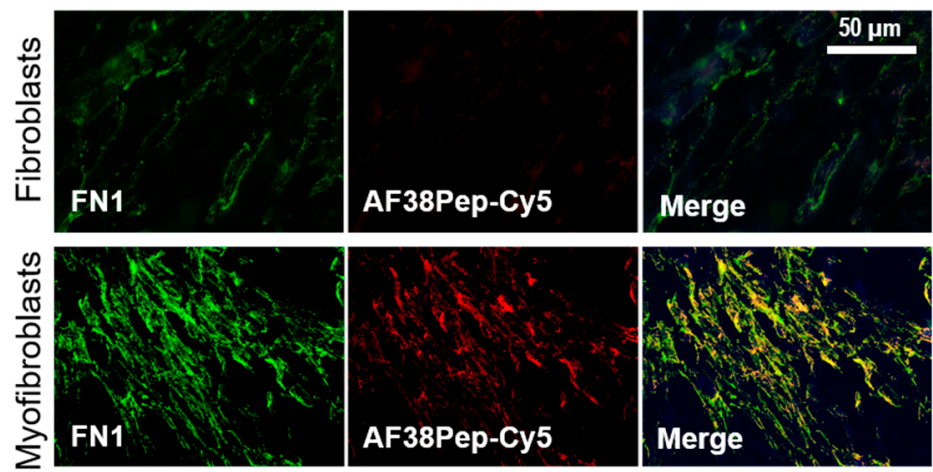

B
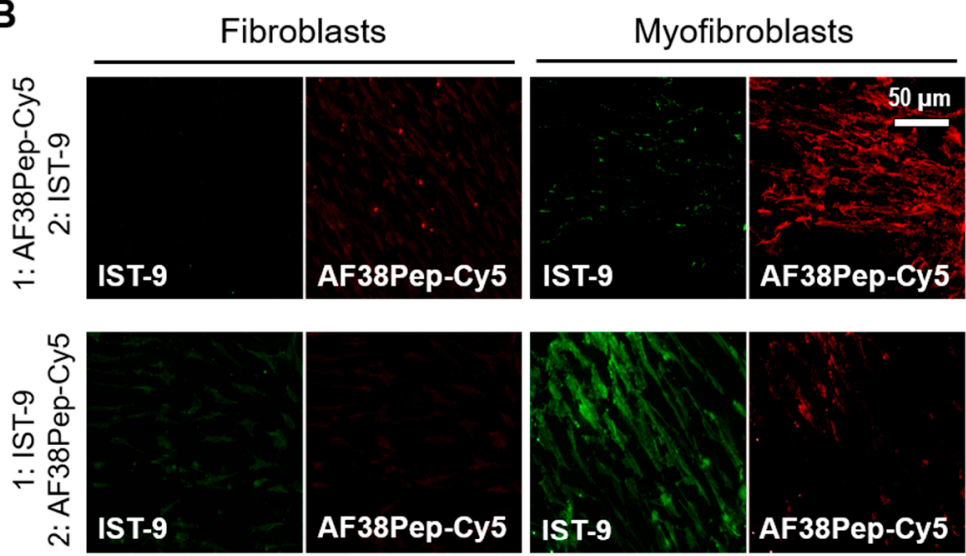

C
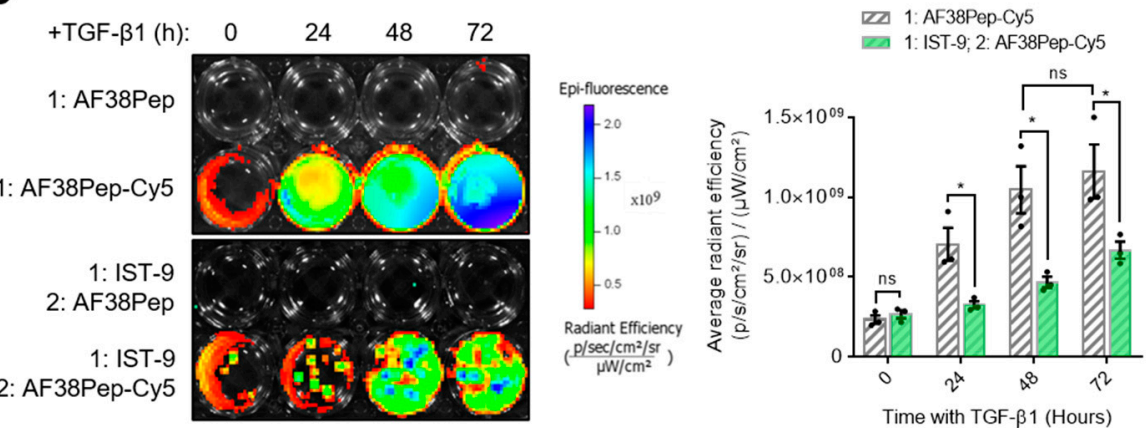

Figure 7. Fibrotic matrix binding characterization of the designed blocking polypeptide. The designed AF38Pep blocking polypeptide was synthesized and conjugated to Cy5 (AF38Pep-Cy5). (A) The extracellular matrices (ECMs) of fibroblasts or differentiated myofibroblasts were fixed and co-labelled with fibronectin (FN1) antibody and AF38Pep-Cy5. Original magnification, $\times 200$; scale bar, $50 \mu \mathrm{m}$. (B) Binding competitiveness was assessed by preincubating fixed matrices with either AF38Pep-Cy5 or IST-9 antibody, followed by incubation with IST-9 or AF38Pep-Cy5, respectively. Original magnification, $\times 200$; scale bar, $50 \mu \mathrm{m}$. (C) Top panel (fibrotic matrix specificity): TGF- $\beta 1$ was used to stimulate EDA-FN production at the indicated timepoints and $10 \mu \mathrm{g} / \mathrm{mL}$ unlabeled AF38Pep or AF38Pep-Cy5 was added for $1 \mathrm{~h}$ before washing and visualization of epifluorescence. Bottom panel (binding specificity): TGF- $\beta 1$ was used to stimulate EDA-FN production at the indicated timepoints and $10 \mu \mathrm{g} / \mathrm{mL}$ IST-9 antibody was preincubated with cells for $1 \mathrm{~h}$. Cells were washed and then $10 \mathrm{\mu g} / \mathrm{mL}$ unlabeled AF38Pep or AF38Pep-Cy5 was added for $1 \mathrm{~h}$ before washing and visualization of epifluorescence. Data are representative of three independent experiments and displayed as the mean \pm S.E. Statistical analysis is shown as ${ }^{*} p \leq 0.05$, and $\mathrm{ns}=$ no statistical significance $(p>0.05)$. 


\subsection{Evaluation of Polypeptide Inhibition of Integrin $\alpha_{4} \beta_{1}$ Signaling}

We next sought to investigate whether events downstream of EDA-FN/integrin $\alpha_{4} \beta_{1}$ binding could be attenuated by our blocking polypeptide. We used Western blotting analysis to examine the signaling proteins, extracellular signal-regulated kinases 1 and 2 (ERK1/2) and focal adhesion kinase (FAK), which were shown to be downstream of integrin $\beta_{1}$ activation [43,44]. Both phosphorylated forms of ERK1/2 and FAK were significantly upregulated after $1 \mathrm{~h}$ of TGF- $\beta 1$ treatment, and this activation was significantly suppressed when cells were also incubated with AF38Pep (Figure 8A). Early signaling events involving the ERK1/2 pathway have been implicated in fibronectin-mediated integrin signaling [45]. Indeed, ERK1/ 2 activation was not prevented at $12 \mathrm{~h}$, when cells were simultaneously incubated with AF38Pep and TGF- $\beta 1$ (Figure 8B). This result may be explained by epidermal growth factor receptor (EGFR) and TGF $\beta$ RI/II pathway-dependent activation of ERK1/2, which induced phosphorylation in a biphasic and time-dependent manner following the stimulation of fibroblasts with TGF- $\beta 1$ [46]. Alternatively, the delayed ERK1/2 signaling may have been in response to FN type III, OPN or VCAM1 binding to their integrin receptor sites at distal locations [47]. However, phosphorylation of FAK protein showed significantly less activation, indicating the prolonged inhibition of the integrin/FAK signaling pathway could be achieved by the AF38Pep blocking polypeptide. Interestingly, total protein levels of FAK were also marginally reduced by the blocking polypeptide at $12 \mathrm{~h}$, suggesting inhibitory actions on the FAK pathway were two-fold; the reduction in activation and reduction in total protein synthesis. Use of the IST-9 antibody resulted in similar signaling inhibition of FAK at $12 \mathrm{~h}$ post-treatment (Figure S1). However, IST-9 prevention of ERK1/2 phosphorylation at the $12 \mathrm{~h}$ timepoint suggested the blockade of additional non-EDAFN-specific ITGA4 activation may have been implicated [47]. Matrix metalloproteinase (MMP) gelatinase release and activity has been associated with fibronectin-dependent activation of integrin $\alpha_{4} \beta_{1}$ and other $\beta_{1}$-containing integrins [48-50]. We used gelatin zymography to assess gelatinase activity in conditioned medium taken from peptide-treated cells (Figure 8 C). The results demonstrated a significant upregulation of both pro-MMP9 and pro-MMP2 gelatinase activity following incubation of fibroblasts with TGF- $\beta 1$ for $48 \mathrm{~h}$ (untreated lane 1 versus TGF- $\beta 1$-treated lane 2 ). Both pro-MMPs exhibited suppressed activity levels when TGF- $\beta 1$-treated fibroblasts were also incubated in the presence of AF38Pep (TGF- $\beta 1$-treated lane 2 versus TGF- $\beta 1+$ AF38Pep-treated lane 4 ). Genes indicative of integrin $\alpha_{4} \beta_{1}$ activation, downstream of TGF- $\beta 1$ stimulation, were also attenuated by AF38Pep treatment (Figure 8D). These included the mRNA expression for MMP9, TGF$\beta 1$, latent-TGF- $\beta$-binding protein 1 (LTBP1), TGF- $\beta 1$-induced transcript 1 (HIC5), and myocardin-related transcription factor A (MRTFA), which gave strong evidence that the polypeptide had successfully blocked the interaction between EDA-FN and integrin $\alpha_{4} \beta_{1}$, and thus prevented the subsequent upregulation of these integrin activation-dependent genes. Overall, the data suggested that AF38Pep interfered with EDA-FN/integrin binding, attenuated FAK-dependent signaling, decreased MMP2 and MMP9 production and activation, and prevented the upregulation of integrin activated gene expression. 
A
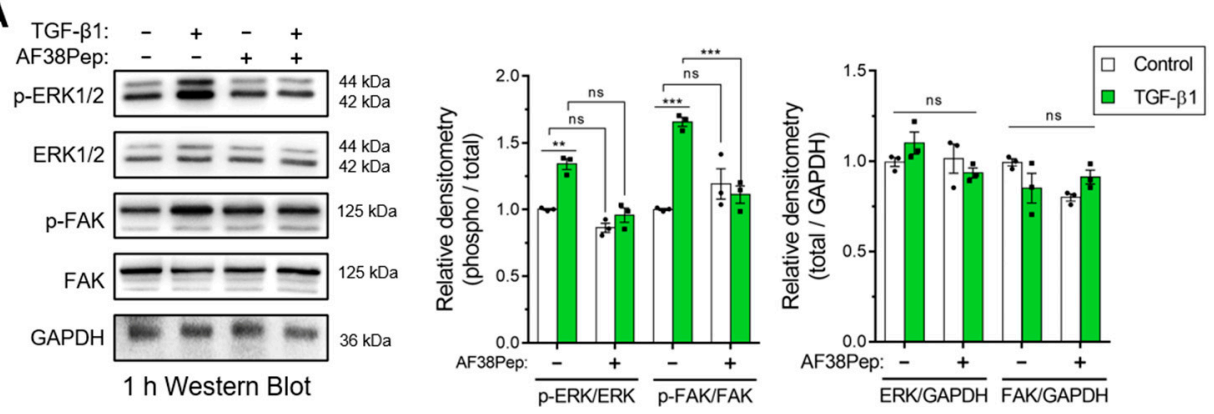

B
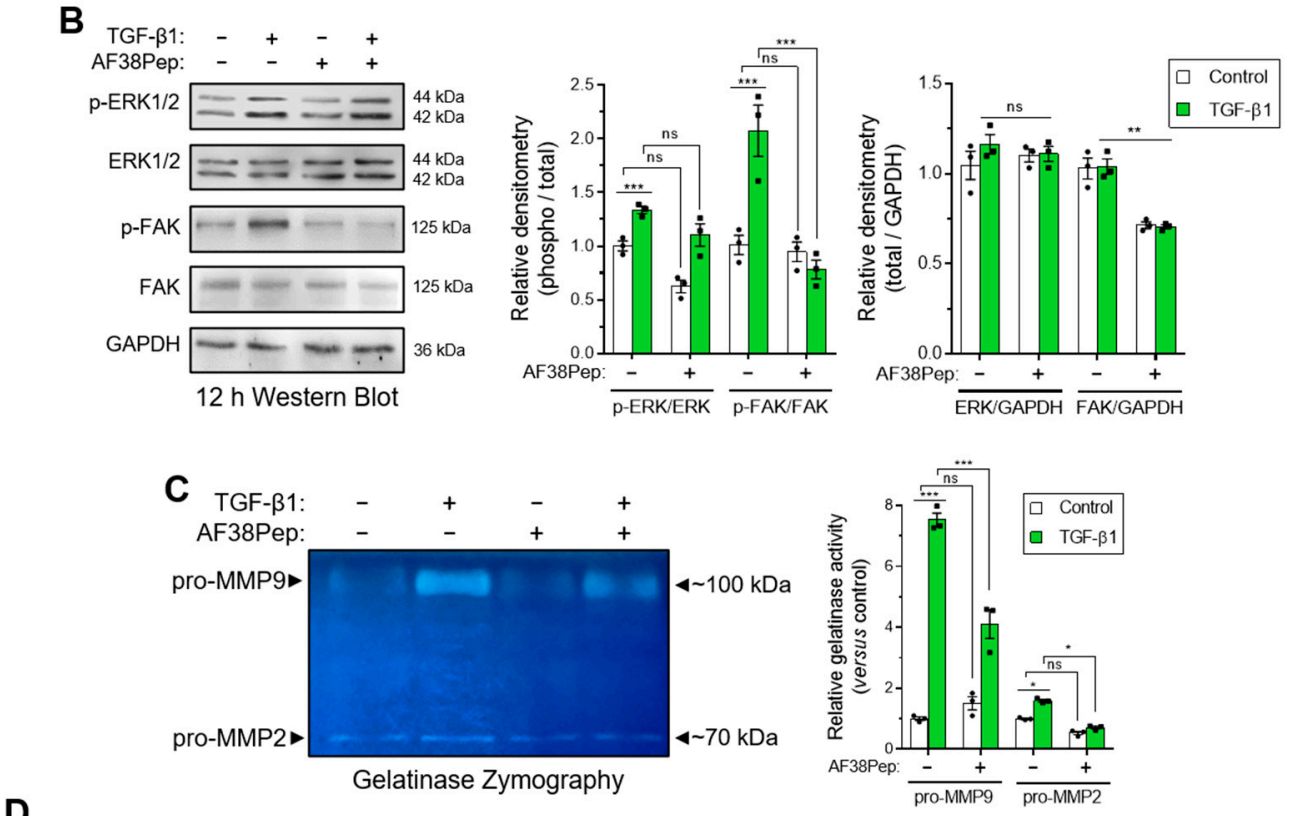

D
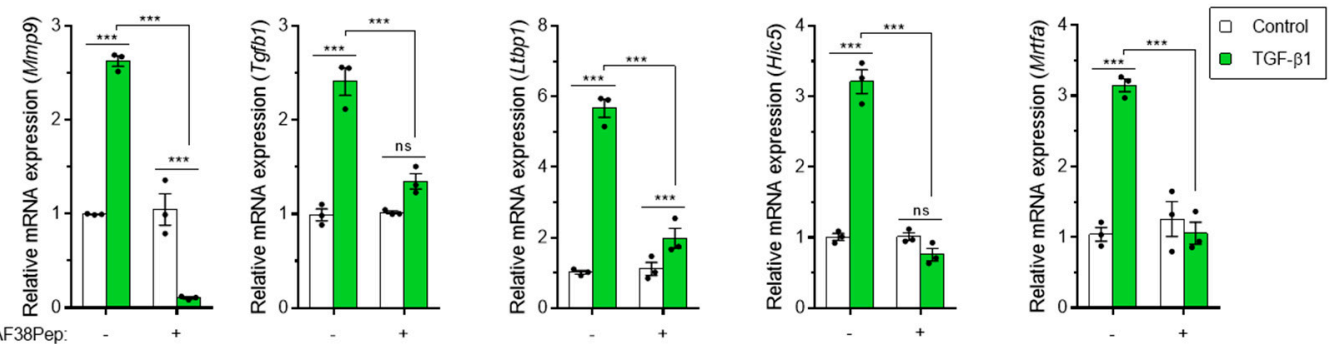

Figure 8. Evaluation of blocking peptide capacity to inhibit integrin $\alpha 4 \beta 1$ signaling and downstream profibrotic effects. $\mathrm{NIH} / 3 \mathrm{~T} 3$ fibroblasts were incubated in the presence or absence of $10 \mathrm{ng} / \mathrm{mL}$ TGF- $\beta 1$ with or without $10 \mu \mathrm{g} / \mathrm{mL}$ AF38Pep for (A) $1 \mathrm{~h}$ or (B) $12 \mathrm{~h}$, before assessment of extracellular-signal-regulated kinases 1 and 2 (ERK1/2) and focal adhesion kinase (FAK) protein expression and phosphorylation. Immunoblots are displayed alongside corresponding densitometry analysis of phospho-protein/total-protein and total-protein/GAPDH loading control. (C) Gelatinase zymography indicating pro-matrix metalloproteinase 9 (pro-MMP9) (top band) and pro-MMP2 (bottom band) enzymatic activity following the indicated treatments for $48 \mathrm{~h}$. Shown alongside is the quantification of relative gelatinase activity. (D) The mRNA expression for genes associated with integrin $\alpha_{4} \beta_{1}$ activation: Mmp9, Tofb1, Ltbp1, Hic5, and Mrtfa, which were assessed by real-time quantitative PCR (qRT-PCR) following $48 \mathrm{~h}$ of stimulation by $10 \mathrm{ng} / \mathrm{mL}$ TGF- $\beta 1$. Blots, images, and data are representative of three independent experiments and data are shown as the mean \pm S.E. Statistical analysis is shown as ${ }^{* * *} p \leq 0.001$, ${ }^{* *} p \leq 0.01,{ }^{*} p \leq 0.05$, and $\mathrm{ns}=$ no statistical significance $(p>0.05)$.

\subsection{Evaluation of Polypeptide Inhibition of Profibrotic Cell Activity}

Immunocytochemistry for $\alpha$-SMA stress fiber formation confirmed the results shown by mRNA analyses (Figure 9, top row). Protein expression of $\alpha$-SMA was inhibited when TGF- $\beta 1$-treated NIH/3T3 dermal fibroblasts also received $10 \mu \mathrm{g} / \mathrm{mL}$ AF38Pep treatment, 
suggesting a lack of myofibroblast phenotypes. Activated fibroblasts reassemble their cytoskeletons to form long F-actin fibers that extend along the length of the cells [51,52]. Thus, we sought to assess whether this process was prevented in AF38Pep-treated cells (Figure 9, bottom row). Our results indicated that although cells failed to acquire enlarged morphologies, cellular actin reassembly into F-actin fibers still occurred in the presence of AF38Pep treatment. This observation suggested that myofibroblast maturation could be attenuated but fibroblasts still progressed to an activated state- often associated with a synthetic fibroblast phenotype (or proto-myofibroblast) with elevated proliferation and migration $[51,53]$. EDA-FN binding to integrins $\alpha_{4} \beta_{1}$ and $\alpha_{4} \beta_{7}$ was shown to be causative of mechano-transduction and resultant collagen-rich ECM production [32,38]. Total collagen synthesis, as determined by hydroxyproline assay (Figure 10A), demonstrated reduced total collagen synthesis to approximately $60 \%$ of that observed in cells that only received TGF- $\beta 1$ treatment, a similar level to collagen production by untreated control fibroblasts. Cell contractility was attenuated by AF38Pep treatment (Figure 10B), which corroborated the inhibition of $\alpha$-SMA incorporation into the cytoskeleton. Cotreatment of AF38Pep alongside TGF- $\beta 1$ stimulation significantly delayed collagen gel contraction by fibroblasts at $96 \mathrm{~h}$ and maintained a significant difference in contraction at $144 \mathrm{~h}$, when compared to TGF- $\beta 1$ stimulation alone. Subsequent analyses of the expression of genes associated with profibrotic myofibroblast phenotypes and indicative of fibrogenesis (Figure 10C) revealed that the upregulated mRNA expressions of collagen types I and III, fibronectin and the EDA-FN splice variant by TGF- $\beta 1$ were all inhibited when AF38Pep was also incubated with the fibroblasts for $72 \mathrm{~h}$. Expression of fibrotic markers in TGF- $\beta 1$ - and AF38Pep-treated cells marginally increased at 24 and $48 \mathrm{~h}$. However, these failed to reach expression levels exhibited by TGF- $\beta 1$-only stimulated cells, with significant attenuation being shown across all assessed genes by $48 \mathrm{~h}$. Overall, the data suggest that AF38Pep interference with EDA-FN/integrin binding prevented the enrichment of collagens and the synthesis of a profibrotic ECM, whilst enabling fibroblasts to enter an activated state, but not permitting the progression to mature myofibroblast phenotypes.

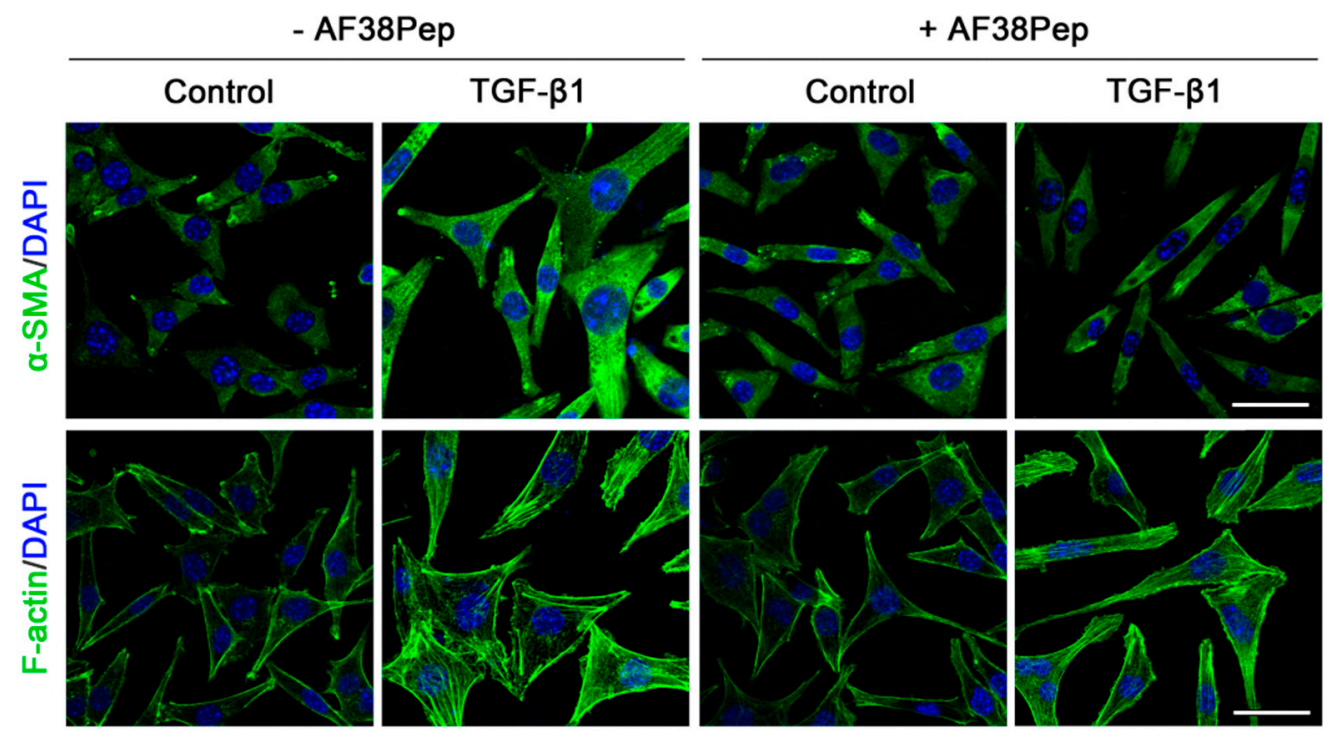

Figure 9. Assessment of blocking peptide effect on myofibroblast phenotype acquisition. NIH/3T3 fibroblasts were incubated in the presence or absence of $10 \mathrm{ng} / \mathrm{mL}$ TGF- $\beta 1$ with or without $10 \mu \mathrm{g} / \mathrm{mL}$ of peptide for $48 \mathrm{~h}$; immunocytochemistry was used to visualize the marker of myofibroblast differentiation ( $\alpha$-SMA, green; DAPI, blue; top row; original magnification, x200; scale bar, $25 \mu \mathrm{m}$ ) and an indicator of fibroblast activation to a proliferative, migratory and synthetic phenotype (F-actin, green; DAPI, blue; bottom row; original magnification, x200; scale bar, $25 \mu \mathrm{m}$ ). Images are representative of three independent experiments. 


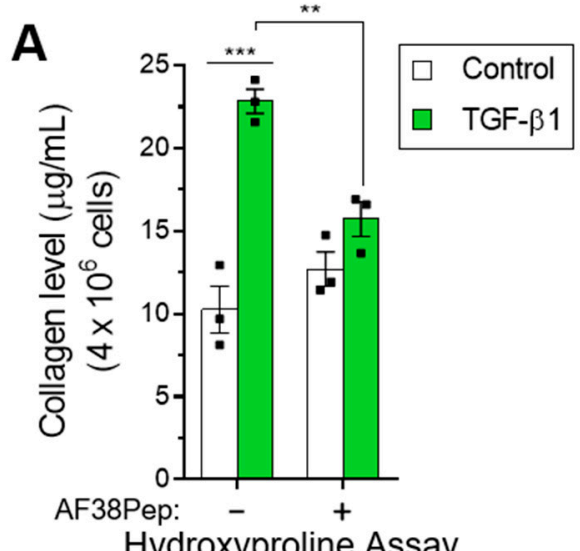

Hydroxyproline Assay
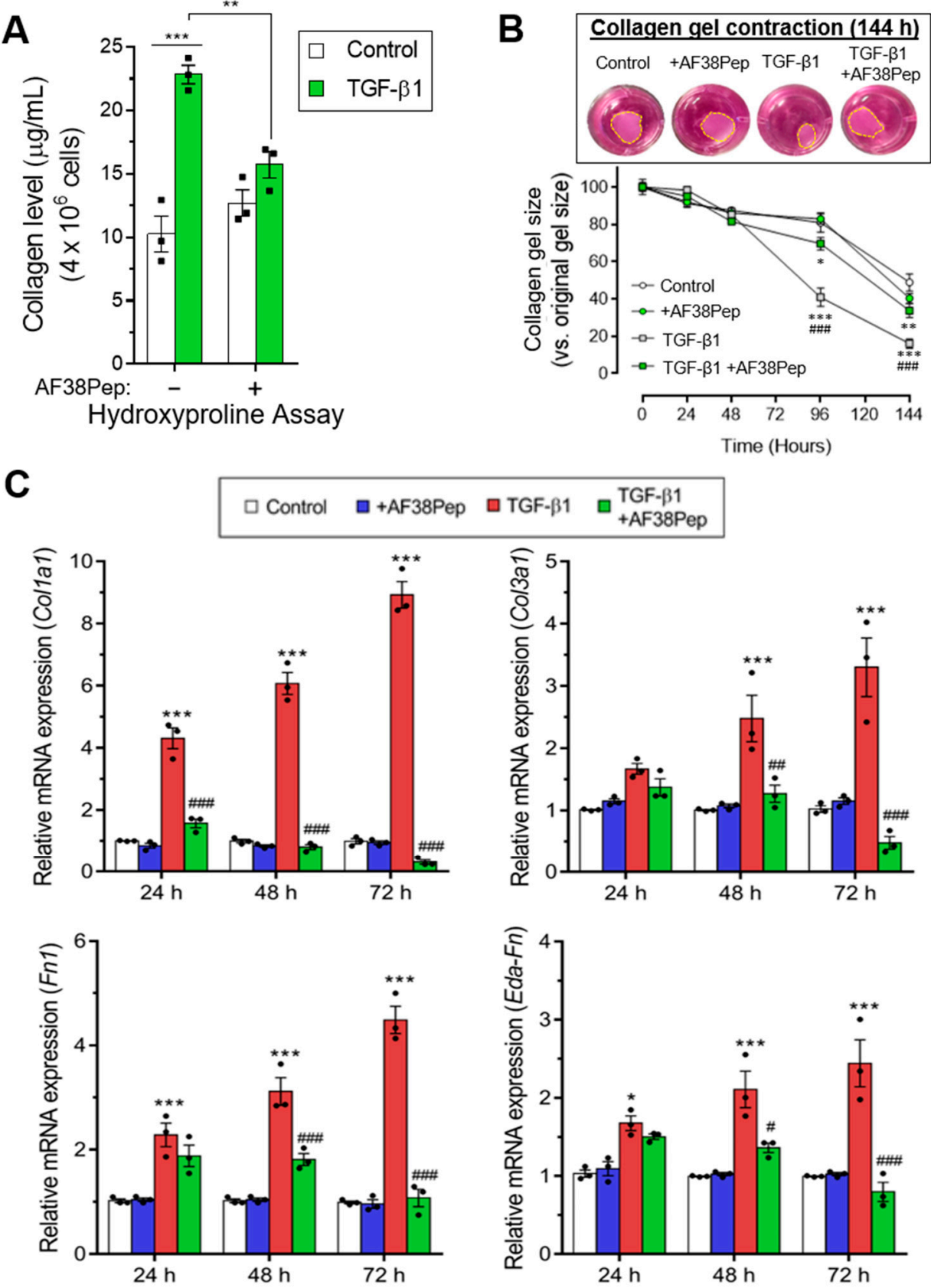

Figure 10. Assessment of blocking peptide effect on profibrotic activity and integrin $\alpha 4 \beta 1$-induced gene expression. (A) The quantification of total collagen production by NIH/3T3 cells as calculated from hydroxyproline assays after $48 \mathrm{~h}$ of treatment time. (B) Collagen gel contraction assay over the course of $144 \mathrm{~h}$ in the absence or presence of the small blocking peptide and $10 \mathrm{ng} / \mathrm{mL}$ TGF- $\beta 1$. The contracted collagen gel images are shown at the $144 \mathrm{~h}$ timepoint. Yellow dashed lines show perimeters of contracted gels. The mRNA expression for (C) fibrosis-associated genes: Col1a1, Col3a1, Fn1, and Eda-Fn1 were assessed by qRT-PCR at 24,48 and $72 \mathrm{~h}$. Data are representative of three independent experiments and shown as the mean \pm S.E. Statistical analysis is shown as ${ }^{* * *} p \leq 0.001$, ** $p \leq 0.01$, and $\mathrm{ns}=$ no statistical significance $(p>0.05)$. \#, \#\#, \#\#\#-statistically significant difference in comparison to TGF- $\beta 1$-only stimulated cells.

\section{Discussion}

The persistent presence of EDA-FN in tissues is a hallmark of fibrosis, synthesized by activated fibroblasts and myofibroblast cells, which continues to drive the development of progressive fibrotic diseases. In this investigation, we used in silico docking simulations 
to design a polypeptide, based on the integrin $\alpha_{4} \beta_{1}$ receptor binding site for the EDA-FN C- $\mathrm{C}^{\prime}$ loop. The polypeptide that performed the best in molecular docking simulations was selected for synthesis and subsequent in vitro assessment. We showed that the EDA-FN binding and blocking polypeptide, that we named AF38Pep, was specific for myofibroblastsynthesized matrices which contain EDA-FN, only associated with the EDA-FN C-C' loop and showed no associations with fibronectin or collagen RGD domains. We also showed that AF38Pep specifically interfered with EDA-FN-integrin $\alpha_{4} \beta_{1}$ interactions, attenuated subsequent ERK1/2 and FAK signaling, and prevented downstream mRNA expression of associated genes. AF38Pep also attenuated collagen synthesis and prevented activated fibroblast differentiation into mature myofibroblasts. The data shown here provide promising evidence for this first generation of EDA-FN small blocking polypeptides that could be implemented in a broad range of pathological conditions related to EDA-FN activity.

The EDGIHEL motif within the EDA-FN C-C ${ }^{\prime}$ region can bind to fibroblast-expressed integrins, including $\alpha_{4} \beta_{1}$ and $\alpha_{4} \beta_{7}$, and the $\alpha_{4}$ subunit was suggested to be an essential EDA-binding component $[30,44,54]$. From the data shown here, in addition to $\alpha_{4}$ motifs, there was clearly strong affinity for the $\beta_{1}$ subunit. When performing in silico assessment of the designed small blocking polypeptides, the polypeptides that consisted of motifs found within the $\beta_{1}$ subunit produced superior binding affinity scores, compared to those that used the $\beta_{7}$ subunit motifs. This suggested that the EDA-FN C- $C^{\prime}$ loop may have a higher binding affinity for integrin receptor dimers that have $\beta_{1}$ subunits. In combination with previous research, it could be speculated that $\alpha_{4} \beta_{1}$ produces the highest binding affinity, whereas integrin $\alpha_{4} \beta_{7}$ may have less affinity due to suboptimal subunit dimer pairings for EDA-FN binding.

The small blocking polypeptide designed as part of this investigation was optimized by mimicking the $\alpha_{4} \beta_{1}$ receptor site. Despite utilizing integrin $\alpha_{4} \beta_{1}$ binding motifs, AF38Pep was designed to bind to the EDA-FN C-C' loop. Thus, in addition to blocking interactions with $\alpha_{4} \beta_{1}$, interactions with other receptors that specifically interact with the EDA-FN C-C' loop may also be prevented by AF38Pep treatment. This broadens the implications of the polypeptide in blocking multiple cell-signaling events that rely on EDA-FN C- $C^{\prime}$ loop binding and activation of receptors and warrants investigation in future studies. Integrin $\alpha_{4} \beta_{7}$ was shown to mediate EDA-FN-induced expression of $\alpha$-SMA containing stress fibers, collagen synthesis, and cellular contractility in lung fibroblasts [32]. Integrin $\alpha_{4} \beta_{1}$ activation by EDA-FN promoted an increase in the assembly of actin and the activation of myosin light chain (MLC), promoted cytoskeletal stress fiber formation, increased fibronectin expression and fibrillogenesis, and led to matrix stiffening but not $\alpha$-SMA incorporation into stress fibers [38]. It is not known whether one of these integrin activation events precedes the other, but matrix stiffening by the upregulated production of EDA-FN is a prerequisite for myofibroblast stress fiber formation, suggesting $\alpha_{4} \beta_{1}$ signaling events leading to matrix deposition may precede $\alpha_{4} \beta_{7}$ signaling leading to stress fiber formation. Regardless of the order of integrin signaling events, AF38Pep had the capacity to attenuate both matrix deposition and $\alpha$-SMA stress fiber formation. These outcomes suggested that AF38Pep was capable of global inhibition of EDA-FN $C^{\prime} C^{\prime}$ loop interactions with cell surface integrins. Although the epithelial-expressed integrin $\alpha_{9} \beta_{1}$ has suggested roles in driving EMT, specific mechanisms of regulation of the transitional events remains unknown [31,54]. EMT in lung and colorectal cancer is accompanied by induction of the expression of mesenchymal markers, including $\alpha$-SMA [54] and vimentin [21], and is thought to be a contributing source of myofibroblasts within fibrotic tissues [55]. Therefore, we speculate that EDA-FN interactions with integrin $\alpha_{9} \beta_{1}$ on epithelial cells may be prevented by AF38Pep treatment. Thus, in addition to treatment of profibrotic disease cell types such as those isolated from keloids and hypertrophic scars [24], the EMT process will also be a focus for future investigations into the broader implications of our designed small blocking polypeptide.

In addition to integrins, a recent study reported EDA-FN-dependent signaling through toll-like receptor 4 (TLR4) drove fibrosis in scleroderma [25]. EDA-FN is a ligand for 
TLR4 and EDA-FN/TLR4 binding resulted in the upregulation of proinflammatory cytokines [56,57]. It was also shown that EDA-FN activated TLR4 expressed on human dermal fibroblasts, induced interleukin-8 (IL-8) and tumor necrosis factor- $\alpha$ (TNF $\alpha$ ) expression [24], and promoted TLR4-dependent synthesis of collagen, which implicated EDA-FN/TLR4 in both proinflammatory and profibrotic cell responses $[6,25,57]$. Whether AF38Pep could also prevent EDA-FN recognition by TLR4 is not known. TLR4 is an inflammatory signaling regulator that warrants investigation, especially in designing therapies against the vicious cycle of chronic inflammation and fibrosis-related pathologies suggested to arise in response to EDA-FN [24,57]. Stromal fibroblast or myofibroblast activation, metastasis, and vasculogenesis have been documented as being initiated by the production of EDA-FN $[20,21,58]$. Therefore, in addition to providing a potential means to block the development of stromal myofibroblasts, AF38Pep may have utility as a targeting or theranostic labelling method for fibrosis or tumors, especially given the rarity of EDA-FN in adult tissues. These various avenues of investigation will form part of future research exploring additional usage of AF38Pep and its broader activities.

Our observations suggested that prolonged FAK activation was attenuated by specific interference with integrin EDA-FN/integrin $\alpha_{4} \beta_{1}$ interactions. Previous reports have suggested that ERK1/2 signaling was mediated by integrin $\alpha_{4} \beta_{7}$ [32]. We observed that early ERK $1 / 2$ signaling at $1 \mathrm{~h}$ post-TGF- $\beta 1$ stimulation was diminished by treatment with AF38Pep, whereas ERK1/2 signaling at $12 \mathrm{~h}$ was not. This may be plausibly explained by previous research that showed that signaling through ERK $1 / 2$ is a temporally controlled process involving multiple receptors [46], or may involve participation from other integrin ligands, OPN and VCAM1 [47]. It remains unclear whether TGF- $\beta 1$ stimulated ERK1/2 activation can be further regulated by integrin signaling in a time sensitive or cyclic manner. In this study, our results suggested that early ERK $1 / 2$ signaling and prolonged FAK activation were dependent on the EDA-FN C-C' loop binding to the integrin $\alpha_{4} \beta_{1}$ or integrin $\alpha_{4} \beta_{7}$ receptor cleft.

Removal of EDA-FN from the genome or proteome has been shown to be detrimental to tissue remodeling during wound healing [18]. Olsen et al. showed that removal of EDA-FN from hepatic stellate cells and portal fibroblasts failed to prevent myofibroblast transdifferentiation in culture or in liver fibrosis models [59]. This unexpected observation was explained in a study by Kawelke et al., wherein genetic deletion of FN increased fibroblast numbers and TGF- $\beta 1$ production, which led to increased fibrosis [60]. This was later confirmed in an investigation by Iwasaki et al. which demonstrated the accumulation of highly disorganized collagenous ECM networks in FN-null liver injury [61]. The unanticipated upregulation in ECM stiffness from increased collagen I-rich matrix deposition and dysregulation of TGF- $\beta 1$ contributed to a more aggressive fibrotic phenotype. Thus, there is clearly a regulatory mechanism of balance in place between FN and collagen synthesis and arrangement, which is important in tuning matrix stiffness and regulating myofibroblast. Therefore, a highly specific blockade of EDA-FN C-C' loop interaction with integrin $\alpha_{4} \beta_{1}$ and the attenuation of downstream intracellular signaling pathways are required for myofibroblast differentiation; inhibiting EDA-FN/integrin $\alpha_{4} \beta_{1}$-mediated myofibroblast formation without unnecessarily interfering with additional collagen and TGF- $\beta 1$ regulating functions of the EDA-FN and other FN variants is a desirable approach. In simpler terms, the EDA-FN macromolecule can remain within the matrix to convey its other important functions, whilst the small blocking peptide can attenuate EDA-FN C-C ${ }^{\prime}$ loop/integrin $\alpha_{4} / \beta_{1}$-dependent signaling.

The blocking polypeptide shown here could serve to prevent initial EDA-FN-dependent myofibroblast transformation and collagen upregulation that would otherwise contribute to the persistence of myofibroblasts in tissues. However, the synthesis and deposition of fibrillar collagen I in progressive fibrosis appears to take over the role of the predominant source of ECM mechanical stress and becomes the principal driver of the myofibroblast phenotype [62]. Therefore, treatment of established fibrosis using EDA-FN blocking antibodies or small blocking polypeptides may be ineffective in reversing the process. However, by 
utilizing AF38Pep as a targeting method, bioactive factors that have been suggested to reverse the myofibroblast phenotype, e.g., BMP7 [52], HGF variants [63], or CD44 variants $[52,64]$ etc., could be conjugated to increase the efficacy of the treatment, preventing new myofibroblast formation whilst reversing the established phenotypes.

In conclusion, the small blocking polypeptide, AF38Pep, was modeled from the $\alpha_{4} \beta_{1}$ receptor binding site for EDA-FN. AF38Pep was subsequently synthesized for use in in vitro assessment of antifibrotic activity and exhibited a prominent antifibrotic effect; reduced TGF- $\beta 1$ stimulated fibronectin and collagen production; prevented integrin signaling through FAK; attenuated downstream release and activation of MMPs, and integrin signaling-associated gene expression, and cumulated in the inhibition of mature myofibroblast formation. The blocking polypeptide reported here has potentially broad applications as an antifibrotic treatment to restrict myofibroblast transdifferentiation, progressive fibrosis, and related diseases.

\section{Materials and Methods}

\subsection{Materials}

Cell culture reagents and plasticware were purchased from Sigma-Aldrich (Poole, Dorset, UK), unless otherwise stated. Custom peptides were synthesized by ChinaPeptides (Shanghai, China). Cells used for experiments were human lung fibroblasts (HFL1; CCL-153, ATCC, Manassas, VA, USA), kindly provided by Professor Wen Ning (Nankai University, Tianjin, China), and mouse dermal fibroblasts (NIH/3T3; CRL-1658, ATCC). TGF- $\beta 1$ was purchased from R\&D Systems (Shanghai, China). All antibodies were purchased from Abcam (Cambridge, UK).

\subsection{Generation of Integrin $\alpha 4 \beta 1$ Protein Model}

Integrin $\beta_{1}$ (ITB1_human) has $42.112 \%$ amino acid sequence homology with integrin $\beta_{7}$ (ITB7_human). Thus, integrin $\alpha_{4} \beta_{7}$ was used as a template upon which the integrin $\beta_{1}$ subunit was mapped onto to create a working integrin $\alpha_{4} \beta_{1}$ model. Chimera v1.13.1 (UCSF, San Francisco, CA, USA) and MODELLER v9.21 (UCSF) (Figure S2) software suites were used to create the integrin $\alpha_{4} \beta_{1}$ model. Briefly, the resolved crystal structures of the $\alpha_{4} \beta_{7}$ head domains (3V4V; RCSB PDB) and the full ITB7_human sequence were used as references for the structural mapping and overlaying of ITB1_human onto the crystal structure of $3 \mathrm{~V} 4 \mathrm{~V}$, and to simulate association with the integrin $\alpha_{4}$ subunit whilst in active conformation. The structural orientations of the integrin $\beta_{1}$ subunits were compared between the newly generated $\alpha_{4} \beta_{1}$ model and the resolved crystal structure of integrin $\alpha_{5} \beta_{1}$ (4WK2; RCSB PDB); similarities between sequence and head domain alignments were used to validate the mapping of the integrins. As a further validation control for predicted binding sites, the integrin $\alpha_{4}$ (ITA4_human) was mapped onto the 4WK2 resolved model, using the integrin $\alpha_{5}$ (ITA5_human) sequence as a reference template. Receptor model quality was assessed and ensured through examination using PROCHECK (EMBL-EBI, Cambridge, UK) (Figure S3) and Verify3D (UCLA-DOE Institute, Los Angeles, CA, USA) (Figure S4).

\subsection{Molecular Docking and Generation of Blocking Peptide Models}

The EDA-FN ligand (YSSPEDGHIEL) and its flanking amino acid sequence were isolated from the NMR structure (1J8K; RCSB PDB) and the structure was minimized with AMBER protocols (AmberTools18, UCSF). Chimera v1.13.1 (UCSF) software suite was used to create the integrin $\alpha_{4} \beta_{1}$ (generated in-house) and integrin $\alpha_{4} \beta_{7}$ (from $3 \mathrm{~V} 4 \mathrm{~V}$ ) receptor docking compatible models, and the EDA-FN peptide docking ligand model. Molecular docking simulations were performed using AutoDock Tools and AutoDock Vina (Scripps Research, San Diego, CA, USA). Briefly, a total of five grids were selected to examine the entirety of the integrin receptor surfaces. Each grid was analyzed individually for simulated molecular docking of the EDA-FN peptide ligand with the AutoDock settings to add polar hydrogens and to perform molecular docking at an exhaustiveness of 8 . The top 
7 binding modes from each analysis were visualized in PyMOL v2.2.3 (Schrödinger K.K., Tokyo, Japan) and colorized based on affinity score. The electrostatic potentials of integrin receptor surfaces, hydrogen bond predictions, and polar contacts between receptor and ligand were assessed using PyMOL v2.2.3 (Schrödinger K.K.) built-in scripts. The PEPSiteFinder tool (RPBS, Paris, France [65]) was used to strengthen predictions of candidate amino acid binding regions. To generate a series of blocking peptides, the amino acids of the integrin receptors that had polar contacts that within a range of $\leq 3 \AA$ with the ligand were listed and the amino acids predicted to form hydrogen bond donors were noted. A series of 10 peptides modeled from the integrin receptor site were generated based on native receptor sequence and the key predicted interacting amino acid regions. Peptides were manually constructed, and initial folding simulations were run in PyMOL v2.2.3 (Schrödinger K.K.). Next, peptides were exported to Chimera v1.13.1 (UCSF) and minimalized by AMBER (UCSF) protocols. Peptides were further assessed and narrowed down to 5 choices based upon AMBER (UCSF), PROCHECK (EMBL-EBI), and RaptorX Contact Prediction (University Chicago, Chicago, IL, USA) scores. The 5 best peptide derivatives were uploaded to PEP-FOLD3 (RPBS [66-68]) and each were assessed for the 5 best folding conformations, which in turn were then assessed for the 5 best binding conformations with the highest docking affinity to the EDA-FN peptide (YSSPEDGHIEL) using AutoDock Vina (Scripps Research). The peptide that had the overall highest binding score was chosen for synthesis and further experimentation.

\subsection{Cell Culture}

HFL1 cells were cultured in Kaighn's modified Ham's F-12 (F-12K) medium (SigmaAldrich) containing $\mathrm{NaHCO}_{3}$ and $\mathrm{HEPES}$ buffered to $\mathrm{pH}$ 7. Cells were grown to confluence in T75 culture flasks in the presence of 10\% fetal bovine serum (FBS; Gibco, Thermo Fisher Scientific, Waltham, MA, USA). HFL1 cells were subcultured using $0.05 \%$ trypsin at a ratio of 1:3. NIH/3T3 cells were cultured in Dulbecco's Modified Eagle Medium (DMEM; HyClone, Thermo Fisher Scientific) containing $100 \mathrm{U} / \mathrm{mL}$ penicillin and $100 \mu \mathrm{g} / \mathrm{mL}$ streptomycin. Cells were grown to confluence in T75 culture flasks in the presence of $10 \%$ FBS. $\mathrm{NIH} / 3 \mathrm{~T} 3$ cells were subcultured using $0.05 \%$ trypsin/EDTA at a ratio of 1:3. All cells were maintained at $37^{\circ} \mathrm{C}$ and $5 \% \mathrm{CO}_{2}$, and growth medium was replenished every 3 days until experimentation. Cells were growth-arrested in serum-free medium for $48 \mathrm{~h}$ before experiments, and all experiments were performed under serum-free conditions using cells between passages 3 and 8 .

\subsection{Cell Viability Assay}

Cells were seeded into 12-well culture plates at a density of $2.5 \times 10^{4}$ and when cultures reached $50 \%$ confluence, the culture medium was replaced with fresh serum-free F12K or serum-free DMEM/F12 for $48 \mathrm{~h}$ (growth arrest). Cells were treated with the indicated concentration of peptide for $48 \mathrm{~h}$ in the presence or absence of $10 \mathrm{ng} / \mathrm{mL}$ TGF- $\beta 1$. Cell Counting Kit-8 (CCK-8; Beyotime, Haimen, China) assays were performed as follows: $10 \%$ of CCK-8 reagent was added to the target wells ( $90 \%$ F12K or $90 \%$ DMEM). CCK-8 utilizes water-soluble tetrazolium salt-SST-8 (WST-8), which is reduced by dehydrogenases of cells, to give soluble orange colored formazan. The amount of the formazan dye generated by dehydrogenase was directly proportional to the number of living cells on plates during the $4 \mathrm{~h}$ incubation period. Medium was aliquoted into wells of a 96-well plate. Absorbance was measured at $450 \mathrm{~nm}$ wavelength using a Bio-Rad optical plate reader.

\subsection{Real-Time Quantitative Polymerase Chain Reaction ( $q R T-P C R$ )}

Reverse transcription (RT) and real-time quantitative PCR (qRT-PCR) were used to assess ACTA2/Acta2, Col1a1, Col3a1, Fn1, Eda-Fn1, Mmp9, Tgfb1, Ltbp1, Hic5, and Mrtfa mRNA expressions. Custom PCR primers were designed in-house (Table 2) and then synthesized by BGI (Beijing, China). Cells were grown in 6-well culture plates and washed with phosphate buffered saline (PBS) before lysis with TRIzon Reagent (CWBio, Beijing, 
China) and total RNA purification according to the manufacturer's protocol. Reverse transcription was carried using the TransScript First-Strand cDNA Synthesis SuperMix kit according to the manufacturer's protocol (TransGen, Beijing, China), using the random primer method for the initiation of cDNA synthesis. Nuclease-free $\mathrm{H}_{2} \mathrm{O}$ replaced the RNA sample to serve as a negative control for the reverse transcription reaction. For qRT-PCR, $10 \mu \mathrm{L} 2 \times$ TransStart Top Green qPCR SuperMix was added to each well of a 96-well PCR plate containing $0.4 \mu \mathrm{L}$ forward primer, $0.4 \mu \mathrm{L}$ reverse primer, $500 \mathrm{ng}$ RNA, and nuclease-free water to a total volume of $20 \mu \mathrm{L}$. The qRT-PCR reaction was completed using a CFX96 Real-Time PCR Detection System (Bio-Rad Laboratories, Hercules, CA, USA). Amplification used the following parameters: $94{ }^{\circ} \mathrm{C}$ for $30 \mathrm{~s}$, followed by 40 cycles of $94{ }^{\circ} \mathrm{C}$ for $5 \mathrm{~s}, 55^{\circ} \mathrm{C}$ for $15 \mathrm{~s}, 72{ }^{\circ} \mathrm{C}$ for $10 \mathrm{~s}$, and then a dissociation stage (melt-curve). Simultaneous qRT-PCR reactions were performed for GAPDH/Gapdh as a standard reference gene and using nuclease-free water in the place of cDNA as a negative control.

Table 2. Custom primers used for qRT-PCR.

\begin{tabular}{ccc}
\hline Primer Target & Forward Primer $\mathbf{( 5}^{\prime} \mathbf{- 3}^{\prime} \mathbf{)}$ & Reverse $^{\text {Primer }} \mathbf{( 5 ^ { \prime } \mathbf { - 3 } ^ { \prime } \mathbf { ) }}$ \\
\hline hsa_ACTA2 & CCGGGACTAAGACGGGAATC & TTGTCACACACCAAGGCAGT \\
hsa_GAPDH & TCGGAGTCAACGGATTTGGT & TGAAGGGGTCATTGATGGCA \\
mmu_Acta2 & CTGACAGAGGCACCACTGAA & ACAATACCAGTTGTACGTCCAGAG \\
mmu_Col1a1 & CTGGTGAACAGGGTGTTCCT & AAACCTCTCTCGCCTCTTGC \\
mmu_Col3a1 & TGGACCTCCTGGAAAAGATG & GAGCCCTCAGATCCTCTTTCA \\
mmu_Fn1 & ACGGTTTCCCATTACGCCAT & GGCACCATTTAGATGAATCGCA \\
mu_Eda-Fn1 & GAATCCAGTCCACAGCCATT & TGAACACTGGGTGCTATCCA \\
mmu_Mmp9 & GACTTTTGTGGTCTTCCCCA & AGCGGTACAAGTATGCCTCTG \\
mmu_Tgfb1 & GGCAGCTGTACATTGACTT & CCTTGCTGTACTGTGTGTCC \\
mmu_Ltbp1 & GGGTGTGTGGATGTGAACGA & GCTGACGATCCACACCTGAA \\
mmu_Hic5 & CTATAGCTGGGCAAGTGGTTA & CAAAAGGGAGCCCCATCCTT \\
mmu_Mrtfa & GCACAGGCATGAGACTGAATTG & AGCTTCAACTGCAGCACTGAC \\
mmu_Gapdh & AAGAGGGATGCTGCCCTTAC & TACGGCCAAATCCGTTCACA \\
\hline
\end{tabular}

\subsection{Isothermal Calorimetry of Peptide Pairs}

Custom designed peptides were resuspended in sterile-filtered HEPES buffered saline (140 mM NaCl, $1.5 \mathrm{mM} \mathrm{Na} \mathrm{HPO}_{4}, 50 \mathrm{mM}$ HEPES; $\mathrm{pH}$ 7). The larger EDA-FN binding peptide was diluted to $15 \mu \mathrm{M}$, degassed and added to the calorimetry chamber well. Three smaller test peptides (fibronectin EDA-peptide, FN-EDA; fibronectin RGD-peptide, FNRGD and collagen I RGD-peptide, COL-RGD) were diluted to $300 \mu \mathrm{M}$, degassed and each was separately loaded into the calorimetry injection needle. The chamber well temperature was kept consistent at $25^{\circ} \mathrm{C}$. Blank buffer was used to replace either the well peptide or the injection needle peptide to account for background heat generation. Isothermal titration calorimetry was performed using a MicroCal iTC200 (Malvern Panalytical, Malvern, UK) and dissociation constant $\left(K_{D}\right)$ and association constant $\left(K_{A}\right)$ were calculated using the one set of sites model fitting (with number of binding sites assumed to be 1 ) in MicroCal Origin Software v8.5 (Malvern Panalytical).

\subsection{Labelling of Peptide with Cy5 and Epifluorescence Assay}

A solution containing 1:1 molar ratio of AF38Pep to non-sulphated Cy5-NHS-ester (APExBIO, Houston, TX, USA) was incubated overnight in RT, shielded from light and under constant mixing. The following day, the solution was passed through a PD-10 Sephadex G-25 M gel filtration column (GE Healthcare, Chicago, IL, USA) into PBS. The first 3 fractions (highest molecular weight) were collected, dialyzed (membrane MWCO $1 \mathrm{kDa}$ ) against $\mathrm{ddH}_{2} \mathrm{O}$ overnight, and concentrated by vacuum centrifuge at $3000 \mathrm{rpm}$ at $60{ }^{\circ} \mathrm{C}$ for $3 \mathrm{~h}$. Fibroblasts were grown to $70 \%$ confluence in 12 -well tissue culture plates, before growth arrest in serum-free DMEM for $48 \mathrm{~h}$. Cells were then treated with $10 \mathrm{ng} / \mathrm{mL}$ TGF- $\beta 1$ for $0,24,48$ and $72 \mathrm{~h}$. The conjugated AF38Pep-Cy5 was added to the plate wells at $10 \mu \mathrm{g} / \mathrm{mL}$ and was incubated for $2 \mathrm{~h}$. The culture medium was removed, and cells 
were washed three times with PBS before replenishment with fresh serum-free DMEM. Any AF38Pep-Cy5 that remained bound to EDA-FN was assessed using an IVIS imaging system (Caliper Life Sciences, PerkinElmer, Hopkinton, MA, USA) set to detect Cy5.5 epifluorescence after excitation at $640 \mathrm{~nm}$. Epifluorescence was quantified using Living Image v4.2 analysis software (Caliper Life Sciences).

\subsection{Western Blot}

Total protein was extracted from cells in RIPA lysis buffer containing $1 \%$ protease inhibitor cocktail, $1 \%$ phenylmethylsulfonyl fluoride, and $1 \%$ sodium orthovanadate (Santa Cruz Biotechnology, Santa Cruz, CA, USA). Protein was quantified by Micro BCA Protein Assay Kit (Thermo Fisher Scientific) before 7.5\% SDS-PAGE and transfer to nitrocellulose. Membranes were blocked with 5\% bovine serum albumin (BSA; Sigma-Aldrich) $/ 0.5 \%$ Tween-20 (Sigma-Aldrich)/PBS for $1 \mathrm{~h}$, RT, followed by incubation with primary antibodies diluted in $1 \%$ BSA $/ 0.1 \%$ Tween-20/PBS, overnight at $4{ }^{\circ} \mathrm{C}$. Primary antibodies were: anti-phosphoY204/Y187 ERK1/2 (1:1000); anti-ERK1/2 (1:1000); anti-phosphoY861 FAK (1:1000); anti-FAK (1:2000). Immunoblotting for anti-GAPDH (1:2500) was used as a protein loading control. Following wash steps, membranes were incubated in goat antirabbit IgG H\&L secondary antibody (horseradish peroxidase, HRP conjugate, 1:10,000) (Abcam; 1:5000 dilution, 1\% BSA/0.1\% Tween-20/PBS). Detection was performed using Immobilon reagent (Merck Millipore, Burlington, MA, USA) and imaged using a Tanon 5500 Chemiluminescent Imaging System (Tanon, Shanghai, China).

\subsection{Coimmunoprecipitation (Co-IP)}

A volume of $25 \mu \mathrm{g}$ total protein from cell lysate in nondenaturing lysis buffer containing protease inhibitors was immunoprecipitated (IP) using anti-ITGA4 antibodies linked to protein A/G sepharose beads (Abcam). IP was completed according to the manufacturer's protocol (ab206996, Abcam). The protein/Ab-bead complexes were centrifuged for $1 \mathrm{~min}$ at $2000 \times g$. Supernatants were discarded, and beads were washed with $0.1 \%$ BSA in PBS. Elution was performed by boiling beads in protein loading buffer for $5 \mathrm{~min}$. Western blotting analysis was performed to determine coeluted proteins.

\subsection{Immunocytochemistry}

Cells were grown to $40 \%$ confluence in 8-well glass chamber slides (Nunc, Thermo Fisher Scientific), prior to growth arrest and treatment. Cells were washed with PBS before fixation in $4 \%$ paraformaldehyde for $10 \mathrm{~min}$ at room temperature. Next, cells were permeabilized with $0.1 \%(v / v)$ Triton X-100 in PBS for $10 \mathrm{~min}$ at room temperature. For visualization of ECM, cells were fixed with $100 \%$ ice-cold methanol for $8 \mathrm{~min}$ at $-20^{\circ} \mathrm{C}$. Slides were washed with PBS and blocked with $1 \%$ goat serum (TBD Science, Tianjin, China) for $30 \mathrm{~min}$ before washing with $0.1 \%(w / v)$ BSA in PBS. Subsequently, slides were incubated with monoclonal mouse anti- $\alpha$-SMA antibody (Sigma-Aldrich, 1:50) diluted in $0.1 \%$ BSA-PBS, overnight at $4{ }^{\circ} \mathrm{C}$. After further wash steps, slides were incubated with goat anti-mouse IgG CF-488 secondary antibody (Abcam, 1:1000) in 0.1\% BSA-PBS for $1 \mathrm{~h}$ at room temperature and under darkness. For F-actin visualization, after fixation and permeabilization; cells were incubated with phalloidin conjugated to FITC (Sigma-Aldrich) in $0.1 \%$ BSA-PBS, overnight at $4{ }^{\circ} \mathrm{C}$. Cells were then mounted in DAPI Fluoromount-G (Thermo Fisher Scientific) and imaged using a Zeiss Axio Imager Z1 UV fluorescence microscope (Zeiss, Jena, Germany) and a Leica TCS SP5 laser scanning confocal microscope (Leica Biosystems, Baden-Württemberg, Germany).

\subsection{Gelatinase Zymography}

Conditioned media were collected from cells incubated with serum-free medium (SFM) alone, SFM containing $10 \mathrm{ng} / \mathrm{mL}$ TGF- $\beta 1$, SFM containing $10 \mu \mathrm{g} / \mathrm{mL}$ AF38Pep, or SFM containing both $10 \mathrm{ng} / \mathrm{mL}$ TGF- $\beta 1$ and $10 \mu \mathrm{g} / \mathrm{mL}$ AF38Pep. Conditioned medium was concentrated $10 \times$ by filtrating spin columns (Amicon Ultra-4 $10 \mathrm{kDa}$ MWCO, Merck 
Millipore) and protein was quantified by Micro BCA Protein Assay Kit (Thermo Fisher Scientific). A $1.5 \mathrm{~mm}$ thick $10 \%$ nonreducing acrylamide gel containing gelatin was prepared and $10 \mu \mathrm{g}$ of sample in $5 \times$ nonreducing buffer was loaded into the gel lanes. The gel was run at $100 \mathrm{~V}$ until the protein entered the stacking gel layer, then the voltage was increased to $150 \mathrm{~V}$ until the marker achieved resolved band separation. The gels were then washed twice for $30 \mathrm{~min}$ using wash buffer to remove SDS and renature the enzymes. Gels were further rinsed for 5-10 min in incubation buffer at $37^{\circ} \mathrm{C}$ with agitation to activate the gelatinase reaction. Fresh incubation buffer was added, and the gels were incubated overnight at $37^{\circ} \mathrm{C}$. Gels were stained with staining solution containing Coomassie blue for between $30 \mathrm{~min}$ to $1 \mathrm{~h}$, before rinsing with $\mathrm{ddH}_{2} \mathrm{O}$ and subsequent incubation with de-stain solution until bands could be observed. The gels were transferred to $2 \%$ acetic acid and rehydrated overnight for imaging by scanner.

\subsection{Hydroxyproline Assay}

Approximately $4 \times 10^{6}$ of TGF- $\beta 1$ - and/or AF38Pep-treated NIH/3T3 fibroblast cells were harvested and homogenized in $1: 1$ conditioned medium to $\mathrm{HCl}(10 \mathrm{~N})$, before incubation at $120^{\circ} \mathrm{C}$ for $24 \mathrm{~h}$ or until complete sample hydrolyzation. Cell-associated and soluble collagen contents were assessed using the Chondrex Hydroxyproline Assay kit (Chondrex, Redmond, WA, USA) according to the manufacturer's protocol. In brief, $10 \mu \mathrm{L}$ of sample, standard or blank control solution was added in duplicate to a 96well clear-bottomed absorbance plate. Next, $100 \mu \mathrm{L}$ of $1 \times$ chloramine-T solution was added to the wells and incubated at room temperature (RT) for $20 \mathrm{~min}$. After incubation, $100 \mu \mathrm{L} 1 \times \mathrm{DMAB}$ solution was added to the wells and incubated at $60^{\circ} \mathrm{C}$ for $30 \mathrm{~min}$, with mild agitation at $5 \mathrm{~min}$ intervals. The plate O.D. values were read at $540 \mathrm{~nm}$ and sample values were compared to the values of the standard curve. The total collagen content was determined using the following equation:

$$
\text { Collagen level }(\mu \mathrm{g} / \mathrm{mL})=\text { Hydroxyproline level }(\mu \mathrm{g} / \mathrm{mL}) \times(100 / 13.5)
$$

\subsection{Collagen Gel Contraction Assay}

Approximately $2 \times 10^{4} / \mathrm{mL} \mathrm{NIH/3T3} \mathrm{fibroblasts} \mathrm{were} \mathrm{added} \mathrm{to} \mathrm{a} \mathrm{solution} \mathrm{containing}$ $3 \mathrm{mg} / \mathrm{mL}$ rat tail collagen type I (BD Biosciences, San Diego, CA, USA), $260 \mathrm{mM} \mathrm{NaHCO}$, $200 \mathrm{mM}$ HEPES and $50 \mathrm{mM} \mathrm{NaOH}$. To each well of a 24-well cell culture plate, $500 \mu \mathrm{L}$ of collagen-cell solution was added and allowed to polymerize at $37^{\circ} \mathrm{C}$ for $1 \mathrm{~h}$. The gels were carefully detached from the well walls before resuspension of gels in 1\% FBS-DMEM and maintained at $37{ }^{\circ} \mathrm{C}$, in a $5 \% \mathrm{CO}_{2}$ atmosphere for $24 \mathrm{~h}$. The DMEM medium was removed and replaced with serum-free DMEM medium with or without $10 \mathrm{ng} / \mathrm{mL}$ TGF- $\beta 1$ and /or $10 \mu \mathrm{g} / \mathrm{mL}$ AF38Pep. Gels were photographed and measured at days 0, 1, 2, 4, and 6 after treatment. The average contraction values were obtained using ImageJ v1.37c (NIH, Bethesda, MD, USA) and are expressed as a percentage of contraction versus the initial gel diameter at 0 days.

\subsection{Statistical Analysis}

For all data with 2 independent variable groupings, two-way analysis of variance (2-way ANOVA) was used, followed by Bonferroni's multiple comparisons and posthoc Tukey's test. Graphical data are expressed as means \pm S.E. of three independent experiments. All data were analyzed using GraphPad Prism v7 (GraphPad Software, San Diego, CA, USA). Where considered statistically significant, analysis was displayed on figures as: ${ }^{*}, p \leq 0.05 ;{ }^{* *}, p \leq 0.01$; and ${ }^{* * *}, p \leq 0.001$, or ns if no significance was found.

Supplementary Materials: The following are available online at https:/ / www.mdpi.com/1422-0 067/22/4/1575/s1, Figure S1: IST-9 antibody blockade of ERK1/2 and FAK signaling at $12 \mathrm{~h}$ postTGF- $\beta 1$ treatment. Figure S2: Modeller scores for ITGB1 mapped to the ITGB7 template. Figure S3: PROCHECK pass results for the $\alpha_{4} \beta_{1}$ 3D receptor model. Figure S4: Verify3D pass results for the $\alpha_{4} \beta_{1} 3 \mathrm{D}$ receptor model. 
Author Contributions: Conceptualization, A.C.M.; Data curation, L.Z. and A.C.M.; Formal analysis, L.Z., H.Y., Y.T. and A.C.M.; Funding acquisition, S.W., D.K. and A.C.M.; Investigation, L.Z., H.Y., Y.X., Y.W. and A.C.M.; Methodology, Y.W., Y.T. and A.C.M.; Project administration, D.K. and A.C.M.; Resources, K.W., Q.Z., S.W. and D.K.; Supervision, K.W., Q.Z., S.W., D.K. and A.C.M.; Validation, L.Z., H.Y., Y.X., Y.W. and A.C.M.; Visualization, L.Z., H.Y. and A.C.M.; Writing-original draft, A.C.M.; Writing-review and editing, D.K. All authors have read and agreed to the published version of the manuscript.

Funding: The work was supported and funded by the National Natural Science Foundation of China (NSFC) Fellowship Fund for International Young Scientists (Grant number: 81850410552); NSFC Project Funding (81830060, 91939112, 81772000); Tianjin Natural Science Foundation (16JCZDJC37600); the Nankai University Fundamental Research Fund for Central Universities (63191125).

Institutional Review Board Statement: Not applicable.

Informed Consent Statement: Not applicable.

Data Availability Statement: The data that support the findings of this study are available from the corresponding author upon reasonable request.

Conflicts of Interest: A.C.M. and D.K. declare the following interests: A.C.M. and D.K. are named inventors on a patent (202011572701.4) that was created as an outcome of the work presented here; all other authors declare no interests.

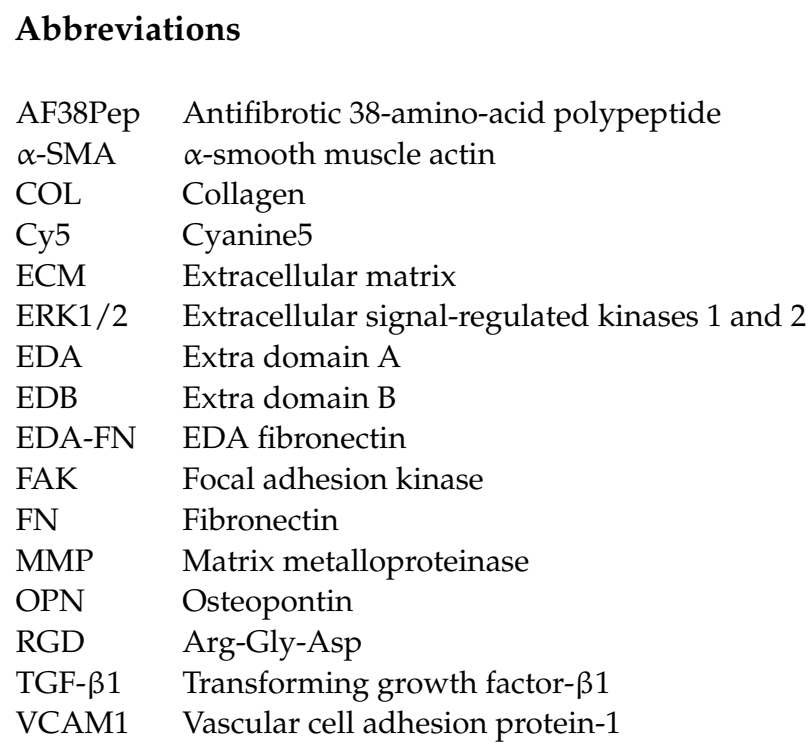

\section{References}

1. Wynn, T.A.; Ramalingam, T.R. Mechanisms of fibrosis: Therapeutic translation for fibrotic disease. Nat. Med. 2012, 18, 1028-1040. [CrossRef] [PubMed]

2. Hinz, B. Masters and servants of the force: The role of matrix adhesions in myofibroblast force perception and transmission. Eur. J. Cell Biol. 2006, 85, 175-181. [CrossRef] [PubMed]

3. Darby, I.; Skalli, O.; Gabbiani, G. Alpha-smooth muscle actin is transiently expressed by myofibroblasts during experimental wound healing. Lab. Investig. 1990, 63, 21-29.

4. Gabbiani, G. The myofibroblast in wound healing and fibrocontractive diseases. J. Pathol. 2003, 200, 500-503. [CrossRef]

5. Kissin, E.Y.; Korn, J.H. Fibrosis in scleroderma. Rheum. Dis. Clin. N. Am. 2003, 29, 351-369. [CrossRef]

6. Yang, R.; Song, Z.; Wu, S.; Wei, Z.; Xu, Y.; Shen, X. Toll-like receptor 4 contributes to a myofibroblast phenotype in cardiac fibroblasts and is associated with autophagy after myocardial infarction in a mouse model. Atherosclerosis. 2018, $279,23-31$. [CrossRef]

7. Bedossa, P.; Paradis, V. Liver extracellular matrix in health and disease. J. Pathol. 2003, 200, 504-515. [CrossRef] [PubMed]

8. Chapman, H.A. Disorders of lung matrix remodeling. J. Clin. Investig. 2004, 113, 148-157. [CrossRef] [PubMed]

9. Eddy, A.A. Molecular basis of renal fibrosis. Pediatr. Nephrol. 2000, 15, 290-301. [CrossRef]

10. Eyden, B.P. Brief review of the fibronexus and its significance for myofibroblastic differentiation and tumor diagnosis. Ultrastruct. Pathol. 1993, 17, 611-622. [CrossRef]

11. Wysocki, A.B.; Grinnell, F. Fibronectin profiles in normal and chronic wound fluid. Lab. Investig. 1990, 63, 825-831. [PubMed] 
12. Desmouliere, A.; Geinoz, A.; Gabbiani, F.; Gabbiani, G. Transforming growth factor-beta 1 induces alpha-smooth muscle actin expression in granulation tissue myofibroblasts and in quiescent and growing cultured fibroblasts. J. Cell Biol. 1993, 122, 103-111. [CrossRef] [PubMed]

13. Rocco, M.; Infusini, E.; Daga, M.G.; Gogioso, L.; Cuniberti, C. Models of fibronectin. EMBO J. 1987, 6, 2343-2349. [CrossRef]

14. Johnson, K.J.; Sage, H.; Briscoe, G.; Erickson, H.P. The compact conformation of fibronectin is determined by intramolecular ionic interactions. J. Biol. Chem. 1999, 274, 15473-15479. [CrossRef]

15. Mao, Y.; Schwarzbauer, J.E. Fibronectin fibrillogenesis, a cell-mediated matrix assembly process. Matrix Biol. 2005, 24, 389-399. [CrossRef] [PubMed]

16. Sens, C.; Huck, K.; Pettera, S.; Uebel, S.; Wabnitz, G.; Moser, M. Fibronectins containing extradomain A or B enhance osteoblast differentiation via distinct integrins. J. Biol. Chem. 2017, 292, 7745-7760. [CrossRef]

17. Jarnagin, W.R.; Rockey, D.C.; Koteliansky, V.E.; Wang, S.S.; Bissell, D.M. Expression of variant fibronectins in wound healing: Cellular source and biological activity of the EIIIA segment in rat hepatic fibrogenesis. J. Cell Biol. 1994, 127, 2037-2048. [CrossRef]

18. Muro, A.F.; Chauhan, A.K.; Gajovic, S.; Iaconcig, A.; Porro, F.; Stanta, G. Regulated splicing of the fibronectin EDA exon is essential for proper skin wound healing and normal lifespan. J. Cell Biol. 2003, 162, 149-160. [CrossRef]

19. Deng, N.; Sanchez, C.G.; Lasky, J.A.; Zhu, D. Detecting splicing variants in idiopathic pulmonary fibrosis from non-differentially expressed genes. PLoS ONE. 2013, 8, e68352. [CrossRef]

20. Xiang, L.; Xie, G.; Ou, J.; Wei, X.; Pan, F.; Liang, H. The extra domain A of fibronectin increases VEGF-C expression in colorectal carcinoma involving the PI3K/AKT signaling pathway. PLoS ONE 2012, 7, e35378. [CrossRef]

21. Ou, J.; Deng, J.; Wei, X.; Xie, G.; Zhou, R.; Yu, L. Fibronectin extra domain A (EDA) sustains CD133(+)/CD44(+) subpopulation of colorectal cancer cells. Stem Cell Res. 2013, 11, 820-833. [CrossRef]

22. Rossnagl, S.; Altrock, E.; Sens, C.; Kraft, S.; Rau, K.; Milsom, M.D. EDA-Fibronectin Originating from Osteoblasts Inhibits the Immune Response against Cancer. PLoS Biol. 2016, 14, e1002562. [CrossRef]

23. Ffrench-Constant, C.; Van de Water, L.; Dvorak, H.F.; Hynes, R.O. Reappearance of an embryonic pattern of fibronectin splicing during wound healing in the adult rat. J. Cell Biol. 1989, 109, 903-914. [CrossRef]

24. Kelsh, R.M.; McKeown-Longo, P.J.; Clark, R.A.F. EDA Fibronectin in Keloids Create a Vicious Cycle of Fibrotic Tumor Formation J. Investig. Dermatol. 2015, 135, 1714-1718. [CrossRef]

25. Bhattacharyya, S.; Tamaki, Z.; Wang, W.; Hinchcliff, M.; Hoover, P.; Getsios, S. FibronectinEDA promotes chronic cutaneous fibrosis through Toll-like receptor signaling. Sci. Transl. Med. 2014, 6, 232ra50. [CrossRef] [PubMed]

26. Muro, A.F.; Moretti, F.A.; Moore, B.B.; Yan, M.; Atrasz, R.G.; Wilke, C.A. An essential role for fibronectin extra type III domain A in pulmonary fibrosis. Am. J. Respir. Crit. Care Med. 2008, 177, 638-645. [CrossRef] [PubMed]

27. Klingberg, F.; Chau, G.; Walraven, M.; Boo, S.; Koehler, A.; Chow, M.L. The fibronectin ED-A domain enhances recruitment of latent TGF-beta-binding protein-1 to the fibroblast matrix. J. Cell Sci. 2018, 131. [CrossRef] [PubMed]

28. Serini, G.; Bochaton-Piallat, M.L.; Ropraz, P.; Geinoz, A.; Borsi, L.; Zardi, L. The fibronectin domain ED-A is crucial for myofibroblastic phenotype induction by transforming growth factor-beta1. J. Cell Biol. 1998, 142, 873-881. [CrossRef] [PubMed]

29. Hinz, B.; Mastrangelo, D.; Iselin, C.E.; Chaponnier, C.; Gabbiani, G. Mechanical tension controls granulation tissue contractile activity and myofibroblast differentiation. Am. J. Pathol. 2001, 159, 1009-1020. [CrossRef]

30. Liao, Y.F.; Gotwals, P.J.; Koteliansky, V.E.; Sheppard, D.; Van De Water, L. The EIIIA segment of fibronectin is a ligand for integrins alpha 9 beta 1 and alpha 4 beta 1 providing a novel mechanism for regulating cell adhesion by alternative splicing. J. Biol. Chem. 2002, 277, 14467-14474. [CrossRef]

31. Shinde, A.V.; Bystroff, C.; Wang, C.; Vogelezang, M.G.; Vincent, P.A.; Hynes, R.O. Identification of the peptide sequences within the EIIIA (EDA) segment of fibronectin that mediate integrin alpha9beta1-dependent cellular activities. J. Biol. Chem. 2008, 283, 2858-2870. [CrossRef] [PubMed]

32. Kohan, M.; Muro, A.F.; White, E.S.; Berkman, N. EDA-containing cellular fibronectin induces fibroblast differentiation through binding to alpha4beta7 integrin receptor and MAPK/Erk 1/2-dependent signaling. FASEB J. 2010, 24, 4503-4512. [CrossRef] [PubMed]

33. Schaffner, F.; Ray, A.M.; Dontenwill, M. Integrin alpha5beta1, the Fibronectin Receptor, as a Pertinent Therapeutic Target in Solid Tumors. Cancers 2013, 5, 27-47. [CrossRef] [PubMed]

34. Brown, A.C.; Dysart, M.M.; Clarke, K.C.; Stabenfeldt, S.E.; Barker, T.H. Integrin alpha3beta1 Binding to Fibronectin Is Dependent on the Ninth Type III Repeat. J. Biol. Chem. 2015, 290, 25534-25547. [CrossRef]

35. Aota, S.; Nomizu, M.; Yamada, K.M. The short amino acid sequence Pro-His-Ser-Arg-Asn in human fibronectin enhances cell-adhesive function. J. Biol. Chem. 1994, 269, 24756-24761. [CrossRef]

36. Vanterpool, F.A.; Cantini, M.; Seib, F.P.; Salmeron-Sanchez, M. A material-based platform to modulate fibronectin activity and focal adhesion assembly. Biores. Open Access 2014, 3, 286-296. [CrossRef]

37. Bachman, H.; Nicosia, J.; Dysart, M.; Barker, T.H. Utilizing Fibronectin Integrin-Binding Specificity to Control Cellular Responses. Adv. Wound Care 2015, 4, 501-511. [CrossRef]

38. Shinde, A.V.; Kelsh, R.; Peters, J.H.; Sekiguchi, K.; Van De Water, L.; McKeown-Longo, P.J. The alpha4beta1 integrin and the EDA domain of fibronectin regulate a profibrotic phenotype in dermal fibroblasts. Matrix Biol. 2015, 41, 26-35. [CrossRef] 
39. Villa, A.; Trachsel, E.; Kaspar, M.; Schliemann, C.; Sommavilla, R.; Rybak, J.N. A high-affinity human monoclonal antibody specific to the alternatively spliced EDA domain of fibronectin efficiently targets tumor neo-vasculature in vivo. Int. J. Cancer 2008, 122, 2405-2413. [CrossRef]

40. Ziffels, B.; Grotsch, A.; Al-Bayati, L.; Neri, D. Targeted delivery of calreticulin to ED-A fibronectin leads to tumor-growth retardation. J. Biotechnol. 2019, 290, 53-58. [CrossRef]

41. Femel, J.; Huijbers, E.J.; Saupe, F.; Cedervall, J.; Zhang, L.; Roswall, P. Therapeutic vaccination against fibronectin ED-A attenuates progression of metastatic breast cancer. Oncotarget 2014, 5, 12418-12427. [CrossRef]

42. Sens, C.; Altrock, E.; Rau, K.; Klemis, V.; von Au, A.; Pettera, S. An O-Glycosylation of Fibronectin Mediates Hepatic Osteodystrophy Through $\alpha_{4} \beta_{1}$ Integrin. J. Bone Miner Res. 2017, 32, 70-81. [CrossRef]

43. Zhao, X.-K.; Cheng, Y.; Cheng, M.L.; Yu, L.; Mu, M.; Li, H.; Liu, Y.; Zhang, B.; Yao, Y.; Guo, H.; et al. Focal Adhesion Kinase Regulates Fibroblast Migration via Integrin beta-1 and Plays a Central Role in Fibrosis. Sci. Rep. 2016, 6, 19276. [CrossRef]

44. Hsia, D.A.; Lim, S.T.; Bernard-Trifilo, J.A.; Mitra, S.K.; Tanaka, S.; den Hertog, J. Integrin alpha4beta1 promotes focal adhesion kinase-independent cell motility via alpha4 cytoplasmic domain-specific activation of c-Src. Mol. Cell Biol. 2005, 25, 9700-9712. [CrossRef]

45. Clark, E.A.; Hynes, R.O. Ras activation is necessary for integrin-mediated activation of extracellular signal-regulated kinase 2 and cytosolic phospholipase A2 but not for cytoskeletal organization. J. Biol. Chem. 1996, 271, 14814-14818. [CrossRef] [PubMed]

46. Midgley, A.C.; Rogers, M.; Hallett, M.B.; Clayton, A.; Bowen, T.; Phillips, A.O. Transforming growth factor-beta1 (TGF-beta1)stimulated fibroblast to myofibroblast differentiation is mediated by hyaluronan (HA)-facilitated epidermal growth factor receptor (EGFR) and CD44 co-localization in lipid rafts. J. Biol. Chem. 2013, 288, 14824-14838. [CrossRef] [PubMed]

47. Yan, Y.; Jiang, F.; Lai, Y.; Wang, H.; Liu, A.; Wang, C. Effect of Thyrotropin on Osteopontin, Integrin alphavbeta3, and VCAM-1 in the Endothelium via Activation of Akt. Int. J. Mol. Sci. 2016, 17, 1484. [CrossRef] [PubMed]

48. Maity, G.; Fahreen, S.; Banerji, A.; Roy Choudhury, P.; Sen, T.; Dutta, A. Fibronectin-integrin mediated signaling in human cervical cancer cells (SiHa). Mol. Cell. Biochem. 2010, 336, 65-74. [CrossRef] [PubMed]

49. Moore, C.; Shen, X.D.; Gao, F.; Busuttil, R.W.; Coito, A.J. Fibronectin-alpha4beta1 integrin interactions regulate metalloproteinase-9 expression in steatotic liver ischemia and reperfusion injury. Am. J. Pathol. 2007, 170, 567-577. [CrossRef] [PubMed]

50. Pal, S.; Ganguly, K.K.; Moulik, S.; Chatterjee, A. Modulation of MMPs by cell surface integrin receptor alpha5beta1. Anticancer Agents Med. Chem. 2012, 12, 726-732. [CrossRef] [PubMed]

51. Avery, D.; Govindaraju, P.; Jacob, M.; Todd, L.; Monslow, J.; Pure, E. Extracellular matrix directs phenotypic heterogeneity of activated fibroblasts. Matrix Biol. 2018, 67, 90-106. [CrossRef] [PubMed]

52. Midgley, A.C.; Duggal, L.; Jenkins, R.; Hascall, V.; Steadman, R.; Phillips, A.O. Hyaluronan regulates bone morphogenetic protein-7-dependent prevention and reversal of myofibroblast phenotype. J. Biol. Chem. 2015, 290, 11218-11234. [CrossRef]

53. Matthijs Blankesteijn, W. Has the search for a marker of activated fibroblasts finally come to an end? J. Mol. Cell Cardiol. 2015, 88, 120-123. [CrossRef]

54. Sun, X.; Fa, P.; Cui, Z.; Xia, Y.; Sun, L.; Li, Z. The EDA-containing cellular fibronectin induces epithelial-mesenchymal transition in lung cancer cells through integrin alpha9beta1-mediated activation of PI3-K/AKT and Erk1/2. Carcinogenesis 2014, 35, 184-191. [PubMed]

55. Menon, M.C.; Ross, M.J. Epithelial-to-mesenchymal transition of tubular epithelial cells in renal fibrosis: A new twist on an old tale. Kidney Int. 2016, 89, 263-266. [CrossRef]

56. Julier, Z.; Martino, M.M.; de Titta, A.; Jeanbart, L.; Hubbell, J.A. The TLR4 agonist fibronectin extra domain A is cryptic, exposed by elastase-2; use in a fibrin matrix cancer vaccine. Sci. Rep. 2015, 5, 8569. [CrossRef]

57. Kelsh-Lasher, R.M.; Ambesi, A.; Bertram, C.; McKeown-Longo, P.J. Integrin alpha4beta1 and TLR4 Cooperate to Induce Fibrotic Gene Expression in Response to Fibronectin's EDA Domain. J. Investig. Dermatol. 2017, 137, 2505-2512. [CrossRef]

58. Ou, J.J.; Wu, F.; Liang, H.J. Colorectal tumor derived fibronectin alternatively spliced EDA domain exserts lymphangiogenic effect on human lymphatic endothelial cells. Cancer Biol. Ther. 2010, 9, 186-191. [CrossRef]

59. Olsen, A.L.; Sackey, B.K.; Marcinkiewicz, C.; Boettiger, D.; Wells, R.G. Fibronectin extra domain-A promotes hepatic stellate cell motility but not differentiation into myofibroblasts. Gastroenterology 2012, 142, 928-937.e3. [CrossRef]

60. Kawelke, N.; Vasel, M.; Sens, C.; von Au, A.; Dooley, S.; Nakchbandi, I.A. Fibronectin protects from excessive liver fibrosis by modulating the availability of and responsiveness of stellate cells to active TGF- $\beta$. PLoS ONE 2011, 6, e28181. [CrossRef] [PubMed]

61. Iwasaki, A.; Sakai, K.; Moriya, K.; Sasaki, T.; Keene, D.R.; Akhtar, R. Molecular Mechanism Responsible for Fibronectin-controlled Alterations in Matrix Stiffness in Advanced Chronic Liver Fibrogenesis. J. Biol. Chem. 2016, 291, 72-88. [CrossRef] [PubMed]

62. Hinz, B.; McCulloch, C.A.; Coelho, N.M. Mechanical regulation of myofibroblast phenoconversion and collagen contraction. Exp. Cell Res. 2019, 379, 119-128. [CrossRef] [PubMed]

63. Dally, J.; Khan, J.S.; Voisey, A.; Charalambous, C.; John, H.L.; Woods, E.L. Hepatocyte Growth Factor Mediates Enhanced Wound Healing Responses and Resistance to Transforming Growth Factor-beta(1)-Driven Myofibroblast Differentiation in Oral Mucosal Fibroblasts. Int. J. Mol. Sci. 2017, 18, 1843. [CrossRef] [PubMed]

64. Midgley, A.C.; Oltean, S.; Hascall, V.; Woods, E.L.; Steadman, R.; Phillips, A.O. Nuclear hyaluronidase 2 drives alternative splicing of CD44 pre-mRNA to determine profibrotic or antifibrotic cell phenotype. Sci. Signal. 2017, 10. [CrossRef] [PubMed] 
65. Saladin, A.; Rey, J.; Thevenet, P.; Zacharias, M.; Moroy, G.; Tuffery, P. PEP-SiteFinder: A tool for the blind identification of peptide binding sites on protein surfaces. Nucleic Acids Res. 2014, 42, W221-W226. [CrossRef]

66. Thevenet, P.; Shen, Y.; Maupetit, J.; Guyon, F.; Derreumaux, P.; Tuffery, P. PEP-FOLD: An updated de novo structure prediction server for both linear and disulfide bonded cyclic peptides. Nucleic Acids Res. 2012, 40, W288-W293. [CrossRef]

67. Shen, Y.; Maupetit, J.; Derreumaux, P.; Tuffery, P. Improved PEP-FOLD Approach for Peptide and Miniprotein Structure Prediction. J. Chem. Theory Comput. 2014, 10, 4745-4758. [CrossRef]

68. Lamiable, A.; Thevenet, P.; Rey, J.; Vavrusa, M.; Derreumaux, P.; Tuffery, P. PEP-FOLD3: Faster de novo structure prediction for linear peptides in solution and in complex. Nucleic Acids Res. 2016, 44, W449-W454. [CrossRef] 